\title{
Decoding abnormal splicing code in human diseases
}

\begin{abstract}
RNA splicing is an intricate process in humans and higher metazoans. Splicing is regulated through multifaceted coordinated factors, such as cis-acting splicing code and RNAbinding splicing trans-factors that associate or compete with ribonucleoproteins (RNPs). Individual cis-acting splicing code and their functional coordination with cognate splicing trans-factors still remain elusive mostgenes, because these code are comprised of highly degenerative short sequence motifs and multiple splicing trans-factors can recognize an identical motif. In addition, a specific splicing motif functions differentially in different genes, which is determined by additional factors such as neighboring sequence context, cell types and association/competition with other splicing trans-factors. Genetic and cellular alterations compromising the fidelity of splicing processes provoke many human diseases. Analyses of abnormal splicing code in human diseases not only uncover the underlying maladies of splicing regulations in pathological conditions, but also allow us to gain insight into splicing mechanisms in physiological conditions. This review introduces accumulating knowledge of numerous modes of splicing aberrations and provides critical information to understand the underlying patho mechanisms of human diseases, which hopefully leads to development of rational therapies.
\end{abstract}

Keywords: alternative splicing, cis-acting splicing code, splicing trans-factor, spliceosome, mutation, aberrant splicing, neurodegenerative diseases, cancers

\author{
Volume 2 Issue I - 2015
}

\begin{abstract}
Kinji Ohno, Mohammad Alinoor Rahman, Farhana Nasrin, Akio Masuda

Division of Neurogenetics, Center for Neurological Diseases and Cancer, Nagoya University Graduate School of Medicine, Japan
\end{abstract}

Correspondence: Kinji Ohno, Division of Neurogenetics, Center for Neurological Diseases and Cancer, Nagoya University Graduate School of Medicine, 65 Tsurumai, Showa-ku, Nagoya, Aichi 466-8550, Japan, Tel +8I 52744 2446, Fax +8I 52 744 2449, Email ohnok@med.nagoya-u.ac.jp

Received: January 09, 2015 | Published: January 21, 2015
Abbreviations: RNPs, ribonucleoproteins; snRNPs, small nuclear ribonucleoproteins; snRNA, small nuclear RNA; BP, branch point; PPT, poly pyrimidine Tract; ISE, intronic splicing enhancer; ESE, exonic splicing enhancer; ISS, intronic splicing silencer; ESS, exonic splicing silencer; SR Proteins, serine/arginine-rich proteins; RRM, RNA-recognition motif; RS Domains, arginine and serine rich domains; hnRNPs, heterogeneous nuclear ribonucleoproteins; ARE, au-rich element; NMD, nonsense mediated decay; AChR, acetylcholine receptor; Fz-CRD, frizzled-like cysteine-rich domain; TE, transposable elements; SINEs, short interspersed nuclear Elements; MIRs, mammalian interspersed repeats; FCMD, fukuyama congenital muscular dystrophy; CMS, congenital myasthenic syndrome; SMA, spinal muscular atrophy; ALS, amyotrophic lateral sclerosis; CLIP, cross-linked immuno precipitation; FTD, fronto temporal dementia; NMJ, neuromuscular junction; $\mathrm{AD}$, alzheimer's disease; DCM, dilated cardiomyopathy; PAR-CLIP, photoactivatable ribonucleoside-enhanced crosslinking and immuno precipitation; NAS, nonsense-associated altered splicing; NASRE, nmd-associated skipping of a remote exon; PTC, premature termination codon; MD, myotonic dystrophy; NSCLC, non-small cell lung cancers; HPT-JT, hyper parathyroidism-jaw tumor syndrome; FIHP, familial isolated primary hyper parathyroidism; FED, fish-eye disease; LQTS, long qt syndrome; CCA, congenital contractural arachnodactyly; IGHD, isolated growth hormone deficiency; FHL3, familial hemophagocytic lymphohistiocytosis; PMD, pelizaeus-merzbacher disease; GHI, growth-hormone insensitivity; RP, retinitis pigmentosa; FTLD, fronto temporal lobar degeneration; ASD, autism spectrum disorders

\section{Introduction}

Humans and other higher metazoans acquired regulated diversity in their genes by inserting multiple noncoding introns into a coding region. At a cost of excising noncoding introns every time a gene is transcribed, we expanded proteome diversity by alternative splicing without increasing the NUMBer of genes. About $95 \%$ of human multiexon genes are estimated to undergo alternative splicing. ${ }^{1,2}$ To support physiological and cellular demand alternative splicing is fine-tuned in tissue-specific, developmental stage-specific and gender-specific manners. It is also modulated in response to external stimuli or intracellular signals. We humans utilize the most complex alternative splicing events. However, with the increase of splicing complexity, splicing processes became readily susceptible to mis regulation, which potentially affects cellular physiology and gives rise to various human diseases. Scrutinized dissection of abnormal splicing mechanisms in human diseases ironically enable us to disclose yet unidentified splicing scenarios in physiological conditions. In this review, we present some examples in which the mechanisms of missplicing are well dissected and implicated in understanding physiological splicing regulations.

\section{Discussion}

\section{Splicing machinery and splicing code}

Splicing of pre-mRNA is carried out in nucleus by spliceosome, which is a macromolecular complex composed of RNA and proteins. Five small nuclear ribonucleoproteins (snRNPs) and multiple proteins $(>100)$ cooperate in spliceosome to catalyze the splicing reaction. Each snRNP is composed of a single uridine-rich small nuclear RNA (snRNA) and multiple proteins. Spliceosome-mediated splicing can be achieved by two steps: recognition of intron/exon boundary and catalysis of the transesterification reaction to excise out an intron followed by joining two exons. Recognition of intron/exon boundary is guided by essential splicing cis-elements close to either end of an intron, termed as consensus splice site sequences (Figure 1a). These include 5' splice site, a branch point (BP), a poly pyrimidine tract (PPT), and 3' splice site. In humans and metazoans, these consensus splice 
site sequences are highly degenerative, which partly compromises appropriate recognition and binding of essential trans-acting factors. As a consequence, multiple auxiliary trans-acting factors need to co-operate to form spliceosome and to favor folding of nuclear premRNA to commit splicing. The assembly of spliceosome is further regulated by auxiliary splicing cis-elements either in a positive or negative manner (Figure 1b). Positively modulating cis-elements are termed as intronic/exonic splicing enhancers (ISEs/ESEs), whereas negatively modulating cis-elements are termed as intronic/exonic splicing silencers (ISSs/ESSs). Most of these auxiliary cis-elements function by binding to cognate trans-factors (Table 1), whereas some cis-elements function by forming secondary structures. The majority of splicing trans-factors for ESE are serine/arginine-rich (SR) proteins, which function as either an essential or regulatory factor. ${ }^{3,4}$ SR proteins can modulate several steps of spliceosome assembly through protein-protein and protein-RNA interaction. ${ }^{5,6}$ They possess one or two RNA-recognition motif (RRM) at the N-terminal end and arginine and serine residues (RS domains) at the $\mathrm{C}$-terminal end. The majority of splicing trans-factors for splicing silencer elements (ISSs/ ESSs) are heterogeneous nuclear ribonucleoproteins (hnRNPs). ${ }^{7}$ Members of this family usually contain an RRM-type and KHtype RNA-binding domain along with other auxiliary domains to mediate protein-protein interaction. ISEs are less well characterized compared to the other cis-elements. Recent analyses on ISEs suggest that hnRNP F, hnRNP H, NOVA1, NOVA2, FOX1, and FOX2 are candidate factors for ISEs. ${ }^{8-11}$

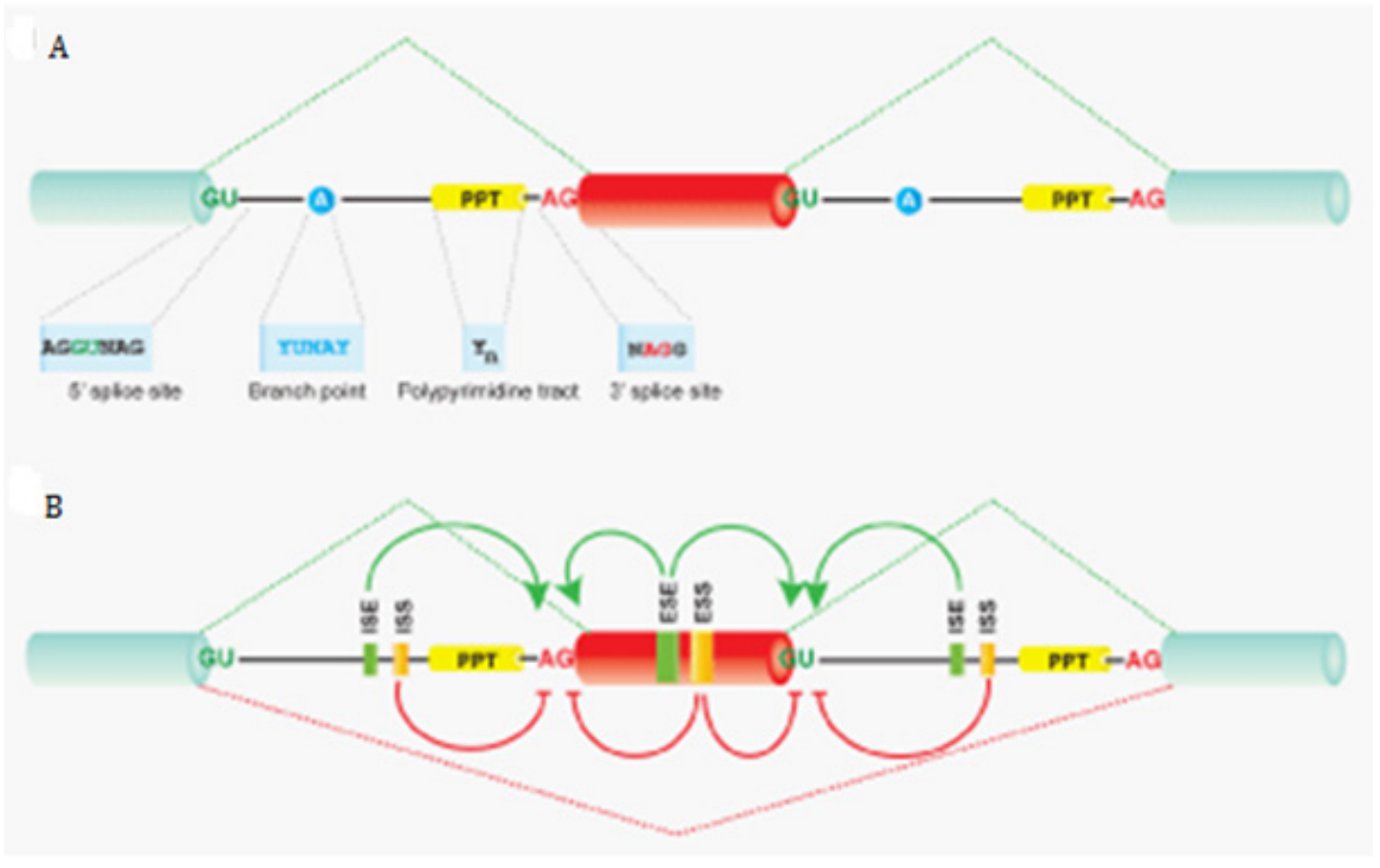

Figure I cis-acting splicing code.

A) Schematic of essential splicing cis-elements: invariant GU and AG dinucleotides constituting the 5' and 3' splice sites, respectively, at the ends of an intron; the branch point (BP, 'A' is observed at 92.3\%); and the polypyrimidine tract (PPT). The consensus sequences of these elements are shown below $(\mathrm{Y}=\mathrm{C} / \mathrm{U}, \mathrm{R}=\mathrm{G} / \mathrm{A}, \mathrm{N}=$ any nucleotide $)$.

B) Schematic of auxiliary splicing cis-elements, which can influence alternative splicing. Based on location and functional activity, these elements can be categorized into intronic/exonic splicing enhancers (ISEs/ESEs) and intronic/exonic splicing silencers (ISSs/ESSs). Recognition of splice sites are promoted by enhancer elements and repressed by silencer elements. In addition, enhancers can antagonize the activity of silencers, and vice versa. Exon inclusion or skipping is finely regulated by the relative strength of these influential elements, which are mostly determined by binding of cognate splicing trans-factors. Activities of splicing trans-factors are also regulated by developmental stage-specific and tissue-specific expression, as well as by phosphorylation and post translational modifications. Therefore, fine-tuned coordination of splicing cis-elements and spatiotemporal expressions of splicing trans-factors is critical to attain the transcriptome and proteome diversities that we human have acquired in the course of evolution.

Spliceosome assembly starts with the recognition of the 5' splice site by U1 snRNP, the BP by SF1, and the PPT as well as 3' terminal AG by $\mathrm{U} 2 \mathrm{AF}$ heterodimer (U2AF65 and $\mathrm{U} 2 \mathrm{AF} 35$, respectively) (Figure 2). This is an ATP-independent initial assembly step termed as an E complex. Initial spliceosome assembly is usually formed across a single intron in a two-exon gene or short introns in multi-exon genes (termed as an intron-defined E complex), whereas it is formed across an exon flanked by long introns in higher metazoans (termed as exondefined E complex). ${ }^{12-14}$ The ATP-independent E complex is then transformed to ATP-dependent spliceosome A complex, where SF1 is replaced by U2 snRNP at BP. Subsequent recruitment of U4/U6-
U5 snRNPs leads to the formation of B complex. Through extensive remodeling and conformational changes, an active spliceosome complex called C complex is formed by replacing U1 and U4 snRNPs, which subsequently catalyzes splicing. In most cases, splicing activators or repressors function by modulating the early spliceosome assembly at the stage of E complex or A complex. Therefore, the ultimate splicing consequence (constitutive splicing or alternative splicing) is determined by complex cis-acting splicing code, their cognate RNA-binding trans-factors and an immense network of their interactions. 
Table I cis-acting RNA motifs recognized by representative splicing regulatory trans-acting proteins

\begin{tabular}{|c|c|}
\hline Protein & Binding sequence \\
\hline \multicolumn{2}{|l|}{$S R$ proteins } \\
\hline SRSFI (SF2/ASF) ${ }^{106-108}$ & SRSASGA, RGAAGAAC,AGGACRRAGC, GGAGA \\
\hline SRSF2 (SC35) & UGCNGYY, GRYYCSYR, AGSAGAGUA, GUUCGAGUA, GA-rich sequence \\
\hline SRSF3 $(S R p 20)^{109,111,112}$ & CCUCGUCC, GCUCCUCUUCC,WCWWC \\
\hline SRSF4 (SRp75) $)^{113,114}$ & GAAGGA, GAUGA, AAGAA, GAAGA, AGAAG, GAAAA \\
\hline SRSF5 (SRp40) $)^{106,115}$ & ACDGS, UGGGAGCRGUYRGCUCGY \\
\hline SRSF6 (SRp55) 106 & USCGKM \\
\hline SRSF7 (9G8) $)^{112}$ & $(\mathrm{GAC}) \mathrm{n}$ \\
\hline \multicolumn{2}{|l|}{ HnRNPs } \\
\hline hnRNPAI $I^{116,117}$ & UAGGG(A/U), UAGG \\
\hline hnRNPA2/B I $117-119$ & (UUAGGG)n, UAG, UAGRGA \\
\hline hnRNP $C^{120,121}$ & Poly-U \\
\hline hnRNP F $F^{117,122}$ & G-rich sequences \\
\hline hnRNP H $H^{117,122}$ & G-rich sequences \\
\hline hnRNP I (PTBPI) $)^{123,124}$ & CU-rich sequences, UYUYU \\
\hline hnRNP L ${ }^{32,125,126}$ & CA-repeat or C/A-rich sequences \\
\hline hnRNP L-like (hnRNP LL) $)^{32,127,128}$ & CA-repeat or C/A-rich sequences \\
\hline \multicolumn{2}{|c|}{ Other splicing regulatory proteins } \\
\hline CUGBPI (CELFI) ${ }^{124,129}$ & U/G-rich sequences \\
\hline ETR3 (CELF2) $)^{130}$ & U/G-rich sequences \\
\hline CELF4'31 & U/G-rich sequences \\
\hline QKI'132,133 & ACUAAY \\
\hline MBNLI |24, 134, 135 & YGCU(U/G)Y \\
\hline FOXI ${ }^{136}$ & (U)GCAUG \\
\hline FOX $2^{136}$ & (U)GCAUG \\
\hline NOVA I 137,138 & YCAY \\
\hline NOVA2 $2^{137,138}$ & YCAY \\
\hline TIAI $^{139}$ & U-rich sequences \\
\hline $\operatorname{TIAR}^{139}$ & U-rich sequences \\
\hline nPTB 140 & CU-rich sequences \\
\hline RBM4 141,142 & CU-rich sequences \\
\hline RBM5 $5^{143-145}$ & CU-rich sequences, GA-rich sequences, poly(G), ANGUAA \\
\hline RBM6 $6^{145}$ & CUCUGAA \\
\hline RBMIO 145 & ANGUAA, CUCUGAA, poly(G), \\
\hline RBM20 $0^{146}$ & UCUU \\
\hline RBM35a (ESRPI) $)^{147}$ & GU-rich sequence \\
\hline RBM35b (ESRP2) ${ }^{147}$ & GU-rich sequence \\
\hline
\end{tabular}

$\mathrm{R}$ (purine) $=\mathrm{A} / \mathrm{G}, \mathrm{Y}$ (pyrimidine)=C/U,W (weak hydrogen bonds)=A/U, S (strong hydrogen bonds)=C/G, $\mathrm{K}$ (keto in a large groove)=G/U, and $\mathrm{M}(\mathrm{amino}$ in a large groove $)=A / C$ 


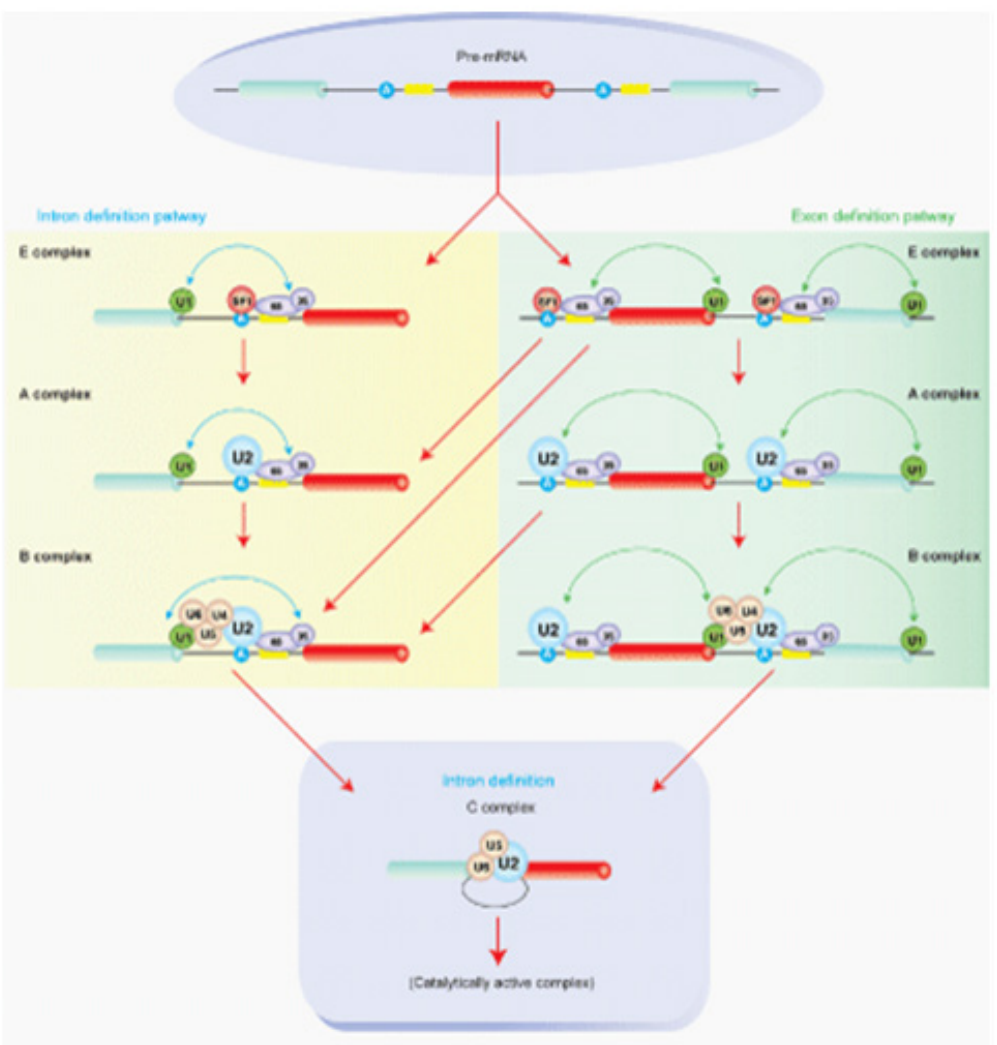

Figure 2 Schematic of major spliceosome assembly on pre-mRNA. The recognition of exon and concomitant intron removal is preceded through the coordinated assembly of spliceosome either across an intron (termed as the intron-definition pathway) or across an exon (termed as the exon-definition pathway). The intron-definition pathway is favored in pre-mRNAs containing a single or short intron, whereas the exon-definition pathway is favored in premRNAs containing a long intron as in metazoans. The progression of spliceosome assembly starts with the recognition of the 5' splice sites by UI snRNP, the BP by SFI, and the PPT as well as 3' terminal AG by U2AF heterodimer consisting of U2AF65 (65) and U2AF35 (35). This is an ATP-independent initial assembly step forming the E complex. The ATP-independent E complex is then transformed to the ATP-dependent spliceosome A complex, where SFI is replaced by U2 snRNP at BP. Subsequent recruitment of U4/U6-U5 snRNPs leads to the formation of the B complex. Through extensive remodeling and conformational changes, the active spliceosome $\mathrm{C}$ complex is formed by replacing $U \mathrm{U}$ and $\mathrm{U} 4$ snRNPs, which subsequently catalyzes splicing. Various lines of evidence demonstrate that transition of spliceosome from exon-definition to intron-definition occurs in the course of splicing of a single exon, which is determined by multiple factors such as the splice site strength, the intron length, regulatory trans-factors, etc. ${ }^{12-14}$ Both the exon-definition and intron-definition pathways merge into formation of the final catalytic $\mathrm{C}$ complex formed across an intron for accurate intron removal.

\section{Pre-mRNA splicing defects cause human diseases}

To support rapidly changing cellular processes, splicing should be rapid and precise. Therefore, correct complement of RNA and proteins in the right cell at the right time is indispensable for strictly regulated biogenesis of ribonucleoprotein complexes (RNPs). Mutations affecting cis-elements, mutations in trans-acting factors and over/ under-expressions of trans-acting factors potentially impair formation of functional spliceosomes. These result in deleterious consequences to cells and underlie a variety of human diseases.

\section{cis-scting splicing defects associated with human diseases}

About 15 to $20 \%$ of human genetic diseases are caused by mutations in the consensus splice site sequences or in the auxiliary splicing ciselements. ${ }^{15}$ cis-acting mutations can interrupt the recognition of both constitutive and alternative splice sites by their cognate trans-acting factors. When a splice site is affected, the aberrantly spliced gene may lack an essential cis-element for mRNA degradation such as AUrich element (ARE). ${ }^{16}$ Similarly, a protein encoded by the aberrantly spliced gene may lack essential domains and signals. Generation of a premature termination codon can give rise to a truncated protein with abnormal functions or activate the nonsense mediated decay (NMD) pathway. In addition, when an alternative splice site is affected, an abnormal change in the ratio of alternative iso forms may compromise cellular processes.

Defects in essential splicing cis-elements: A lot of human diseases are due to mutations in consensus splice sites (see some examples in Table 2). The consensus of the 5' splice site is "CAG/GUAAGU" where "/" denotes an exon-intron boundary. ${ }^{17,18}$ This site is recognized by U1 snRNP. In humans and other higher eukaryotes, BP sequences are highly degenerative, whereas yeast has a strictly conserved BP sequence of 'UACUAAC'. ${ }^{19}$ To elucidate a consensus sequence of human BP, we analyzed 367 lariat RT-PCR clones arising from 52 introns of 20 human housekeeping genes and disclosed that the consensus human BP sequence is " $\mathrm{yUnAy}$ " $(\mathrm{y}=\mathrm{C} / \mathrm{U}$ and $\mathrm{n}=$ any nucleotide).$^{20}$ The fourth nucleotide " $\mathrm{A}$ " is the branch point (position +0 ) and is conserved in $92.3 \%$ of the clones. The "U" at position -2 is conserved in $74.6 \%$. Collation of 46 experimentally confirmed BPs in previous reports also gave rise to our BP consensus sequence of "yUnAy". Extensive analyses of human BPs using RNA-seq data similarly revealed that the consensus sequence is "UnAy". ${ }^{21,22}$ 
Table 2 Representative cis-acting defects associated with aberrant splicing

\begin{tabular}{|c|c|c|c|}
\hline Gene & Mutation & Consequence & Disease \\
\hline \multicolumn{4}{|c|}{ Disruption of consensus splice sites } \\
\hline \multicolumn{4}{|c|}{ 5'splice site-disrupting mutations } \\
\hline HRPT2 $2^{148}$ & IVS2+IG>C & Exon 2 skipping & Hyperparathyroidism-jaw tumor syndrome (HPT-JT) \\
\hline HRPT2 $2^{149}$ & $|V S I+| G>A$ & $\begin{array}{l}\text { Partial deletion } \\
\text { (30bp) of exon I }\end{array}$ & Familial isolated primary hyperparathyroidism (FIHP) \\
\hline $\mathrm{CHRNE}^{150}$ & IVS7+2T>C & Intron 7 retention & Congenital myasthenic syndrome (CMS) \\
\hline \multicolumn{4}{|c|}{ Branch point-disrupting mutations } \\
\hline LCAT $^{151}$ & IVS4-22T>C & Intron 4 retention & Fish-eye disease (FED) \\
\hline $\mathrm{KCNH} 2^{152}$ & IVS9-28A/G & Intron 9 retention & Long QT syndrome (LQTS) \\
\hline $\mathrm{FBN} 2^{153}$ & IVS30-26T>G & Exon 3I skipping & Congenital contractural arachnodactyly (CCA) \\
\hline \multicolumn{4}{|c|}{ Polypyrimidine tract-disrupting mutations } \\
\hline FANCA $^{154}$ & c.7I0-5T>C & Exon 8 skipping & Fanconi anemia \\
\hline RBI ${ }^{155}$ & IVS8-IOT>C & Exon 9 skipping & Retinoblastoma \\
\hline DFNA5 $5^{156}$ & IVS7-DCTT & Exon 8 skipping & Nonsyndromic hearing impairment \\
\hline \multicolumn{4}{|c|}{ 3'splice site-disrupting mutations } \\
\hline HPRT2 $^{157}$ & IVS2-IG>A & Exon 3 skipping & HPT-JT \\
\hline CSPG $2^{158}$ & IVS7-2A>G & Activation of a cryptic splice site & Wagner syndrome \\
\hline $\mathrm{CHRNE}^{159}$ & IVS6-IG>C & Activation of a cryptic splice site & CMS \\
\hline \multicolumn{4}{|c|}{$\begin{array}{l}\text { Disruption of auxiliary splicing cis- } \\
\text { elements }\end{array}$} \\
\hline \multicolumn{4}{|c|}{ ESE-disrupting mutations } \\
\hline COLQ $1^{60}$ & p.E4I5G & Exon 16 skipping & CMS \\
\hline $\mathrm{CHRNE}^{76}$ & p.EFI57V & Exon 6 skipping & CMS \\
\hline $\mathrm{BRCAI}^{88}$ & p.G5I99T & Exon I8 skipping & Breast and ovarian cancer \\
\hline \multicolumn{4}{|c|}{ ESS-disrupting mutations } \\
\hline CHRNA ${ }^{32}$ & $P 3 A 23^{\prime} G>A$ & Exon P3A inclusion & CMS \\
\hline MAPT $^{161}$ & p.N269N & Exon 10 inclusion & Neurodegenerative tauopathies \\
\hline PTPRC 162 & p.C77G & Skipping of multiple exons & Multiple sclerosis \\
\hline \multicolumn{4}{|c|}{ ISE-disrupting mutations } \\
\hline $\mathrm{GHI}{ }^{163}$ & IVS3+28G >A & Exon 3 skipping & Isolated growth hormone deficiency (IGHD II) \\
\hline UNCI3D 164 & $\mid V S I+525 G>T$ & Retention of an intronic segment & Familial hemophagocytic lymphohistiocytosis (FHL3) \\
\hline PLPI ${ }^{165}$ & IVS3D28-46 & Alternative 5' splice site selection & Pelizaeus-Merzbacher disease (PMD) \\
\hline \multicolumn{4}{|c|}{ ISS-disrupting mutations } \\
\hline CHRNAI ${ }^{27}$ & IVS3-8G>A & Exon P3A inclusion & CMS \\
\hline ATM $^{166}$ & $\begin{array}{l}4 \text { bp deletion in } \\
\text { intron } 20\end{array}$ & Activation of a cryptic exon & Ataxia-telangiectasia \\
\hline GHR ${ }^{167}$ & c. $618+1800 A>G$ & Activation of a cryptic exon & Inherited growth-hormone insensitivity (GHI) \\
\hline
\end{tabular}


A high degree of degeneracy of human BP sequences suggests that recognition of human BP is likely to be cooperated along with downstream PPT where U2AF65 binds and possibly the invariant AG dinucleotide at the 3 ' splice site where U2AF35 binds. In PPT, uridines are preferred over cytidines. ${ }^{23,24}$ PPT with eleven continuous uridines is highly competent and the position of such PPT is not critical. ${ }^{23}$ On the other hand, PPTs with only five or six uridines are required to be located close to the 3' AG for efficient splicing. ${ }^{23}$ It is interesting to note that introns carrying a long stretch of PPT favors the binding of U2AF65 so strong that binding of U2AF35 to 3' splice site becomes dispensable, which is called "AG-independent 3' splice site". In contrast, when the PPT is short, binding of U2AF35 becomes indispensable for splicing, which is called "AG-dependent 3' splice site". Again, the proximity between BP and the 3' splice site is sometimes a critical factor for splice site selection..$^{24}$ Therefore, a synergistic co-regulatory process decides the efficient recognition of the intron/exon boundary at the 3' splice site. The first nucleotide of an exon $\left(\mathrm{E}^{+1}\right)$ is also sometimes correlated with splicing. Mutations at $\mathrm{E}^{+1}$ is also prevalent in human diseases, but is less analyzed compared to the invariant ' $A G$ ' at the 3' splice site. We dissected the splicing effects of mutations at $\mathrm{E}^{+1}$, and found that an $\mathrm{E}^{+1}$ mutation causes aberrant splicing at an AG-dependent splice site and normal splicing at an AG-independent splice site. ${ }^{25}$ We reported five mutations at $\mathrm{E}^{+1}$, which caused aberrant splicing. In the course of our analysis, we detected that in the human genome, $\mathrm{T}$ is preferentially selected at exonic positions $+3,+4$ and +5 , which was partly consistent with a previously reported in vitro SELEX study demonstrating that $\mathrm{U} 2 \mathrm{AF} 35$ can bind up to 12 nucleotides downstream from the intronexon boundary. ${ }^{26}$ In the U2AF35-selected RNA pool, enrichment of $\mathrm{T}$ at exonic positions $+3,+4$ and +5 were indeed evident. Although, splicing mutations affecting $\mathrm{T}$ nucleotide at these exonic positions have not been reported so far, but we assume that some of these mutations confer susceptibility to aberrant splicing.

Defects in auxiliary splicing cis-elements: In addition to mutations affecting the consensus splice sites, mutations affecting auxiliary cis-elements (ISEs/ESEs and ISSs/ESSs) also have profound effects on aberrant splicing. These mutations may silence, enhance or switch the activity (silencing to enhancing, and vice versa) of splicing regulatory cis-elements. We have summarized representative examples of aberrant splicing in human diseases due to the defect in auxiliary splicing cis-elements in Table 2 . A remarkable example of the detrimental effect of a single nucleotide mutation was evident in CHRNA1 encoding the muscle nicotinic acetylcholine receptor alpha subunit. CHRNA1 harbors an inframe alternatively spliced exon P3A and inclusion of this exon disables assembly of the acetylcholine receptor $(\mathrm{AChR})$ subunits and subsequently prevents their expression on the cell surface. In two different patients suffering from congenital myasthenic syndrome, a point mutation was identified in each patient with striking physiological consequences (Figure 3a) (Figure 3b). The first mutation (IVS3-8A>G) in intron 3 was identified at the eighth nucleotide preceding exon P3A (Figure 3a). ${ }^{27}$ Detailed analysis demonstrated that the mutation disrupts an ISE and compromises the binding of a cognate trans-factor, hnRNP H. This subsequently causes exclusive inclusion of exon $\mathrm{P} 3 \mathrm{~A}$, which impedes the cell surface expression of AChR. As a result, neuromuscular signal transmission is compromised due to a reduction of AChR density at the patient end plate. The mechanisms in the second patient were more complicated (Figure $3 \mathrm{~b}$ ). A missense mutation identified at the $23^{\text {rd }}$ nucleotide of exon P3A (P3A23'G>A) causes aberrant inclusion of exon P3A and subsequently compromises neuromuscular signal transmission at the patient end plate. Mechanistic analysis revealed that the mutation gains a de novo binding affinity for a splicing enhancing factor, hnRNP LL, and displaces binding of a splicing suppressing factor, hnRNP L. The hnRNP L interacts with another splicing repressor PTB through the proline-rich region and promotes PTB binding to the polypyrimidine tract upstream of exon P3A. Interaction of hnRNP $\mathrm{L}$ with PTB inhibits association of U2AF65 and U1 snRNP with the upstream and downstream splice sites flankingexon P3A respectively, which causes a defect in exon P3A definition and promotes exon skipping. In contrast, hnRNP LL lacks the proline-rich region and cannot interact with PTB. HnRNP LL thus antagonizes hnRNP L-mediated stabilization of PTB and U2AF65 and U1 snRNP are able to associate with the upstream and downstream splice sites flanking exon P3A, which leads to inclusion of exon P3A.

Binding of antagonizing splicing trans-factors to an identical site is observed in SMN1 and SMN2 (Figure 3c). SMN1 and SMN2 are highly homologous paralogs with only a single nucleotide substitution. SMN1 and SMN2 carry C and T, respectively at the 6th nucleotide of exon 7. Splicing of SMN1 exon 7 is enhanced by SRSF1. ${ }^{28,29}$ A C-to-T substitution at the 6th nucleotide of exon 7 in SMN2 gains binding of a splicing-suppressing hnRNP A1. ${ }^{30,31}$ In addition, the C-to-T substitution may ${ }^{28,29}$ or may not ${ }^{30,31}$ abolish binding of SRSF1. In contrast to hnRNPs L and LL for CHRNA $1,{ }^{32}$ however SRSF 1 and hnRNP A1 do not compete for binding to an identical site. Although no splicing mutations have been reported, we recently reported that exon 10 of MUSK encoding the muscle-specific receptor tyrosine kinase, MuSK, is alternatively spliced in human but not in mouse. ${ }^{33}$ MuSK mediates AChR clustering at the motor endplate and exon 10 encodes a frizzled-like cysteine-rich domain (Fz-CRD), which is essential for Wnt-mediated AChR clustering. In MUSK exon 10, binding of hnRNP C promotes binding of YB-1 and hnRNP L to the immediate downstream sites and these three molecules cooperatively enhance skipping of exon 10. As the splicing cis-elements are within exon 10, mutations affecting MUSK potentially cause exon skipping, but no mutations reported to date affect these elements.

Defects in RNA secondary structure: In addition to disruption of consensus and auxiliary splicing cis-elements, mutations may affect the RNA secondary structure, which also have a critical role in premRNA splicing. ${ }^{34-37}$ The most commonly shared feature is the presence of structural elements that interfere with the accessibility of essential splicing factors to the cognate cis-elements. In some cases, structural constraints outside the essential cis-elements can also affect splicing process indirectly by modulating the relative distance between splice sites, thereby generating variability in splice site recognition efficiency. In addition, RNA structural features have also been documented to affect the accessibility of auxiliary splicing cis-elements (ESEs/ISEs and ESSs/ISSs). Therefore, genetic defects can potentially affect splicing by altering the RNA secondary structures, which can give raise to devastating pathological abnormalities in humans. The RNA secondary structure and its association with human disease has been deeply dissected in splicing of human tau exon $10 .^{38-41}$ Mutations in the tau gene (MAPT) are associated with frontotemporal dementia and Parkinsonism. A cluster of mutations is located at an RNA stem-loop structure at the 3' end of exon 10. This stem-loop structure restricts the accessibility of U1 snRNP to the 5' splice site and thereby critically regulates alternative splicing of tau exon 10 to attain a physiological ratio of exon 10-skipped and included transcripts. Mutations in this region destabilize the stem-loop structure and subsequently increase the splice site usage due to an enhanced recognition by U1 snRNP. As a result, physiological balance of the two transcripts is disrupted owing to the abnormal production of an exon 10-included tau isoform, which leads to tau aggregates in neuronal and glial cells. 


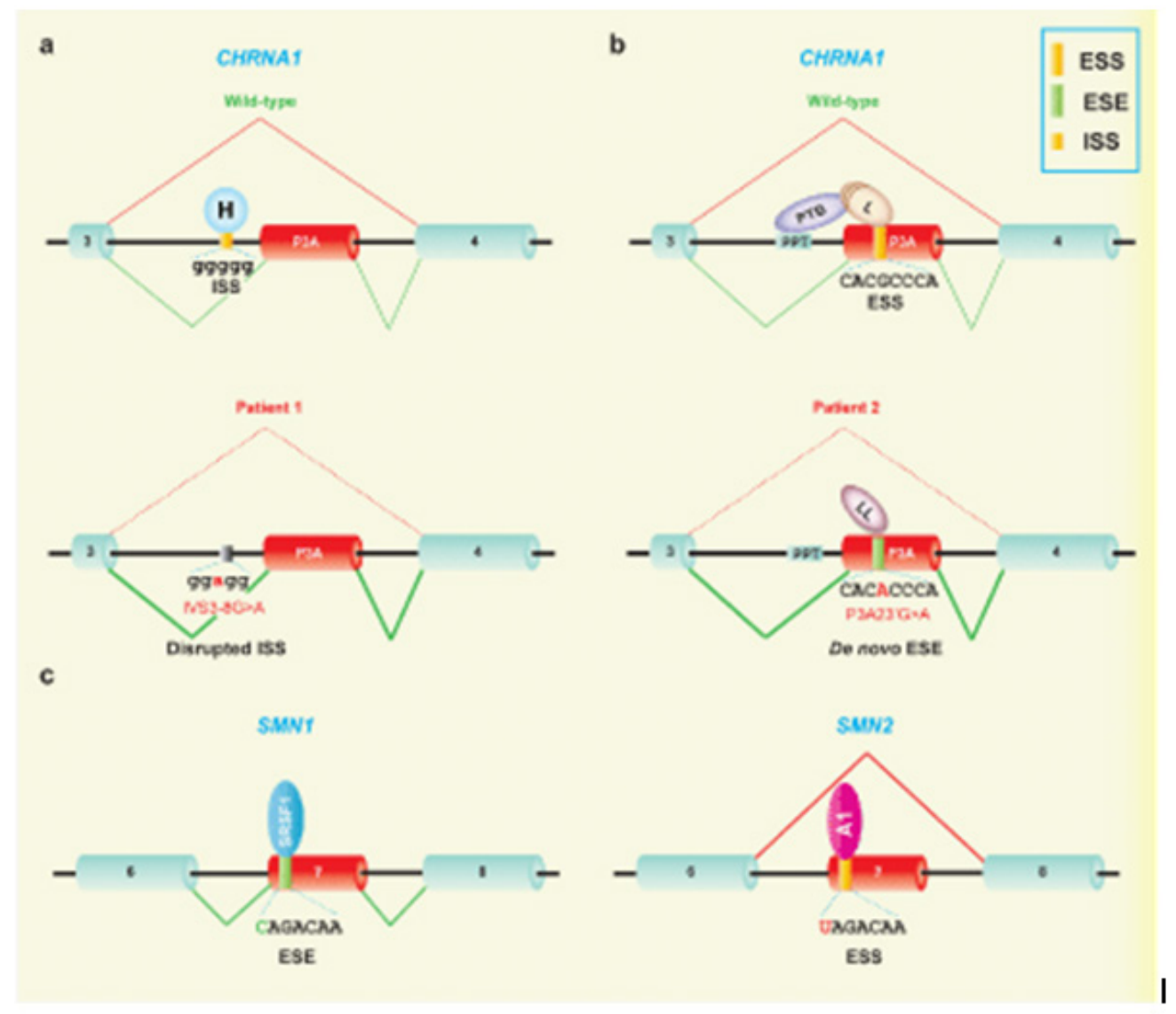

Figure 3 Splicing consequences due to disruption of cis-acting splicing code.

A) In a patient with congenital myasthenic syndrome (CMS), a mutation in intron 3 (IVS3-8G>A) of CHRNAI disrupts an intronic splicing silencer (ISS) by compromising the binding of its cognate factor, hnRNP H $(\mathrm{H}){ }^{27}$ This causes an exclusive inclusion of a nonfunctional exon P3A, which disrupts the assembly of acetylcholine receptor (AChR) on the cell surface, thereby compromises neuromuscular signal transmission at the patient endplate.

B) In a second patient with CMS, a missense mutation in exon P3A ( $\left.33 \mathrm{~A}_{2} 3^{\prime} \mathrm{G}>\mathrm{A}\right)$ of CHRNAI disrupts binding of a splicing suppressing RNA-binding protein, $h n R N P L(L)$, and de novo generates a binding affinity for a splicing enhancing RNA-binding protein, hnRNP LL (LL). ${ }^{32} \mathrm{HnRNPL}$ normally stabilizes binding of another splicing repressor, PTB to the upstream polypyrimidine tract (PPT) of P3A, which is disrupted due to the mutation.As a result, aberrant inclusion of exon P3A is observed with subsequent maladies at the patient endplate.

C) Spinal muscular atrophy (SMA) is characterized by degeneration of spinal motor neurons and is caused by loss-of-function mutations in the survival of motor neuron I gene (SMNI). SMNI and SMN2 are nearly identical paralogues, which carry $\mathrm{C}$ and T, respectively, at the 6th nucleotide of exon 7. Inclusion of SMNI exon 7 is enhanced by SRSFI through an ESE. ${ }^{28,29} \mathrm{~A}$ C-to-T substitution at the 6th nucleotide of exon 7 inactivates the binding of splicing enhancing SRSFI ${ }^{28,29}$ and gains binding of splicing-suppressing hnRNPAI(AI). ${ }^{30,31}$ As a result, a functionally compromised exon 7-skipped isoform (SMN7) is produced, which cannot compensate for the loss of SMNI in SMA, leading to progressive degeneration of spinal motor neurons.

\begin{abstract}
Aberrant activation of cryptic splice site: Another class of splicing defect is the activation of a cryptic splice site, which causes retention of a segment within an intron. Inclusion of an intronic segment in spliced mRNA often causes disruption of the open reading frame or generation of a premature termination codon. Abnormal activation of a cryptic splice site has been reported in many human diseases. ${ }^{42}$ Activation of a cryptic splice site is mostly due to a mutation generating a de novo splicing donor or acceptor site within an intron. The generated splice site usually possesses higher splice site strength over the native splice site, as measured by in Silico web programs. Alternatively, inactivation or deletion of a native splice site can also potentiate the selection of a cryptic splice site. A rare mechanism was identified in Duchenne muscular dystrophy, where genomic inversion causes activation of cryptic splice sites. ${ }^{43}$
\end{abstract}

Cryptic exonization: Besides cryptic splice site activation, a closely relevant event is cryptic exonization, which is mediated by transposable elements (TE), originating from short interspersed nuclear elements (SINEs) and mammalian interspersed repeats (MIRs) ${ }^{44}$ In most cases, insertion of TE into the host gene directly causes cryptic exonization of the inserted TE. In some cases, a second mutation on the inserted TE is required to activate cryptic exonization. An example of direct exonization is the fukutin gene (FKTN), where cryptic exonization of a TE inserted at the 3' UTR of FKTN produces a transcript isoform encoding a nonfunctional protein with an altered C-terminus, leading to Fukuyama congenital muscular dystrophy (FCMD). ${ }^{45}$ Another interesting example is exon P3A of CHRNA1 gene, which we discussed in the previous section. Exon P3A and its flanking intronic regions have been arisen from exonization of the retroposed mammalian interspersed repeat element (MIR) ${ }^{46}$ Inclusion of this inframe exon P3A disables assembly of the AChR subunits. In human skeletal muscle, the $\mathrm{P} 3 \mathrm{~A}(-)$ and $\mathrm{P} 3 \mathrm{~A}(+)$ transcripts are generated in a 1:1 ratio. ${ }^{47}$ Acquisition of exon $\mathrm{P} 3 \mathrm{~A}$ is predicted to be detrimental for human, because exclusive inclusion of 
exon P3A would compromise neuromuscular signal transmission by reducing $\mathrm{AChR}$ expression at the endplate. Indeed in two individual cases, mutations causing exclusive inclusion of exon P3A give rise to congenital myasthenic syndrome (CMS), which is characterized by abnormal muscle fatigue, muscle weakness, amyotrophy and sometimes minor facial anomalies (Figure 3). ${ }^{27,32}$

\section{Trans-acting splicing defects causing human diseases}

Compared to cis-acting splicing defects, trans-acting defects can potentially exert a more detrimental consequence, because multiple target genes can be affected by a defect of a single trans-factor. The affected trans-factors can be either an essential constituent of splicing machinery or an auxiliary factor modulating alternative splicing. The defect can be either a genetic mutation in a trans-factor itself or nongenetic aberration affecting the fidelity of recruitment of a transfactor to spliceosome. Both can lead to altered splicing efficiency of both constitutive and alternative exons. Nongenetic aberrations of trans-factors include abnormal expression, post-translational modification, and subcellular localization of trans-factors (Figure 4).

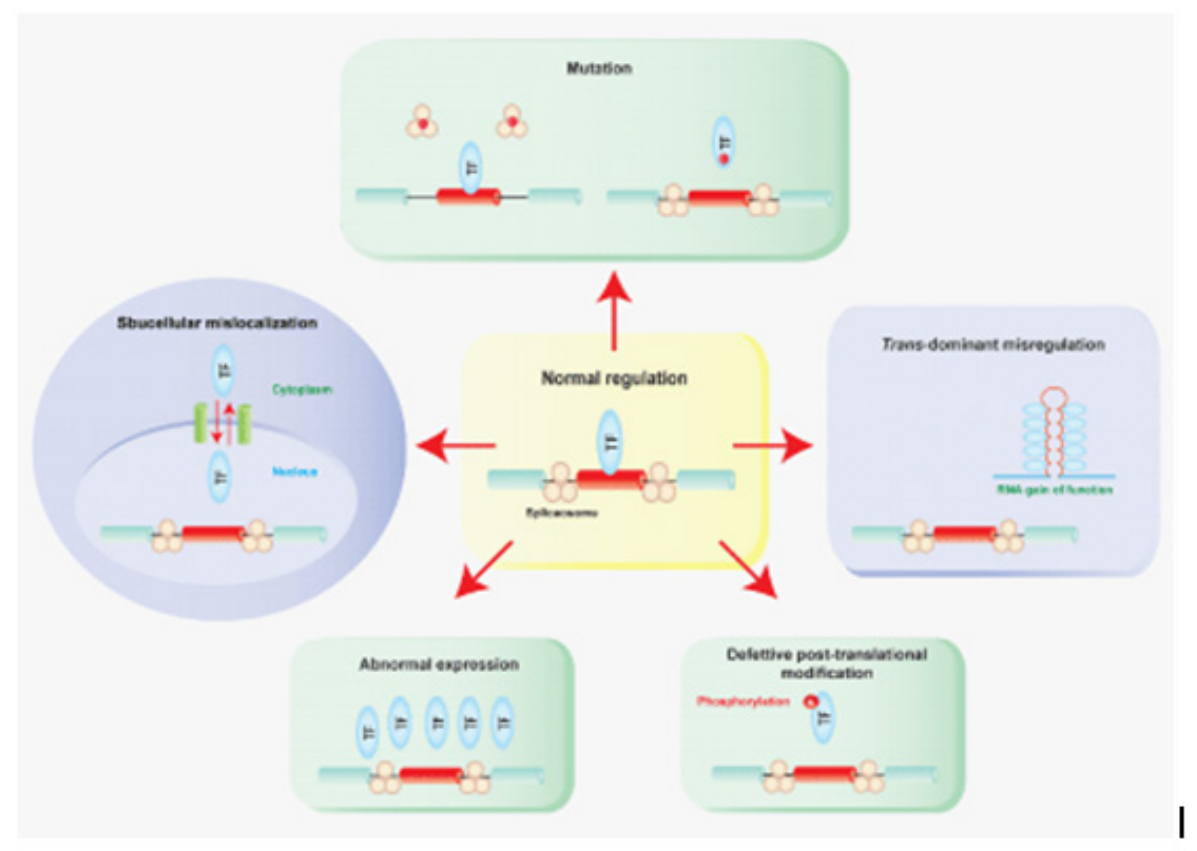

Figure 4 Models of trans-acting splicing defects. Schematic summary of different mode of splicing aberrations due to defects in trans-acting splicing factors including mutations in both essential and auxiliary trans-factors, subcellular mislocalization, abnormal expression, defective post-translational modification, and trans-dominant splicing defects. TF indicates a trans-factor.

Defects in essential splicing factors: Mutations in the core spliceosome components have been identified as a potential cause of many human splicing diseases in recent years (Table 3). A striking example is myelodysplasia characterized by deregulated dysplastic blood cell production with predisposition to acute myeloid leukemia. In a study of whole-exome sequencing of 29 myelodysplasia specimens, mutations involving multiple components of spliceosome have been demonstrated as the cause of pathogenesis. ${ }^{48}$ The mutations are mostly in $S F 3 B 1, S R S F 2, U 2 A F 35$, and ZRSR2 and less frequently in SF3A1, SF1, U2AF65 and PRPF40B. These mutated trans-factors are confined to spliceosome E complex and A complex, suggesting that compromised function of spliceosome E/A complex is a potential cause of myelodysplasia. Another interesting example is autosomal dominant forms of retinitis pigmentosa (Table 3), which is caused by the loss of retinal rod photoreceptor cells due to mutations in the essential splicing factors of PRPF3, PRPF8, PRPF31 and RP9. ${ }^{49} \mathrm{~A}$ defect in the biogenesis of essential spliceosome components is also exemplified in spinal muscular atrophy (SMA), which is caused by the deficiency of SMN leading to motor neuron degeneration. SMN complex is essential for biogenesis of snRNPs and SMN-deficiency perturbs the stoichiometry of snRNAs, which causes wide-ranging pre-mRNA splicing defects in numerous genes. ${ }^{50}$
First, TDP-43 regulates alternative splicing. For example, TDP43 displays a substantial binding affinity for the microsatellite region (UG)nin intron 8 of CFTR(a gene mutated in cystic fibrosis) and subsequently induces skipping of exon $9 .{ }^{54}$ This causes generation of a functionally compromised exon 9-skipped protein isoform, which was previously demonstrated to be associated with cystic fibrosis and congenital bilateral absence of the vas deferens. ${ }^{55,56}$ To further address the nuclear dysfunction, in vivo RNA targets of TDP-43 have been extensively identified by cross-linked immunoprecipitation (CLIP)seq. ${ }^{57,58}$ CLIP-seq revealed that TDP-43 preferentially regulates splicing of mRNAs that are important for brain development and synaptic function. The TDP-43 targets include CTNND1, MEF2D, BIM, AP2, CNTFR, MADD, CDK5RAP2, KIF2A, KIF1B, SOX9, TLE1, $T N I K, U N C 5 C$, etc., but their direct relevance to neuro degeneration remains to be elucidated. ${ }^{58}$ Second, TDP-43 shuttles between the nucleus and cytoplasm, but mostly remains in the nucleus. ${ }^{59}$ In several neurological diseases including frontotemporal dementia (FTD), ALS, and Alzheimer's disease, TDP-43 is accumulated in cytoplasmic inclusions in the patient's brain, which is subsequently ubiqutinated, cleaved, and abnormally phosphorylated..$^{60,61}$

Third, TDP-43 plays an important role in axonal transport of mRNAs. In normal human brain, binding of TDP-43 to 3' UTR of 
mRNAs is 10-fold enriched in the cytoplasm compared to the nucleus, suggesting a role of TDP-43 in mRNA stability and transport. ${ }^{58}$ TDP-43 interacts with two distinct groups of proteins constituted of a nuclear/ splicing cluster and a cytoplasmic/translation cluster, suggesting that TDP-43 exerts different roles in the nucleus and cytoplasm. ${ }^{62}$ One of the cytoplasmic functions of TDP-43 is to constitute cytoplasmic mRNP granules and guide delivery of target mRNA from the soma to distal axonal compartments including neuromuscular junction (NMJ). ${ }^{59}$ They also proved that TDP-43 mutations in ALS impair transport of the target mRNAs to distal axonal compartments. Pathomechanisms of TDP-43 mutations can thus be attributed to defects in splicing of target pre-mRNA due to compromised spliceosome formation, and/ or defects in distal axonal transport of target mRNAs. Both abnormal nucleo cytoplasmic shutting of TDP-43 and abnormal cytoplasmic aggregates of TDP-43 potentially exert additional deleterious effects on the nuclear and cytoplasmic roles of TDP-43. Tauopathies are a characteristic pathological feature of neurodegenerative disorders, including Alzheimer's disease, where abnormal accumulation of tau proteins occurs due to alteration in its metabolism. At least three types of alterations are observed; aberrant splicing of exon 10 of tau protein, missense mutation, and aberrant hyperphosphorylation. ${ }^{63,64}$ Glycogen synthase kinase (GSK-3) is a key enzyme that positioned at the convergence of pathways that are misregulated in Alzheimer's disease and other tauopathies. Several modes of regulation of GSK-3 have been demonstrated including tau hyperphosphorylation, modulation of presenilin, and amyloid toxicity. ${ }^{63,64}$ In addition, GSK-3 regulates splicing of tau exon 10 by modulating SC35 phosphorylation and intracellular distribution, which is altered in some tauopathies. ${ }^{63}$

Table 3 trans-acting defects associated with aberrant splicing

\begin{tabular}{|c|c|c|c|}
\hline Gene & Defect & Consequence & Disease \\
\hline \multicolumn{4}{|c|}{ Defects in essential trans-factors in spliceosome } \\
\hline \multicolumn{4}{|l|}{$S F 3 B I$} \\
\hline \multicolumn{4}{|l|}{ SF3AI, } \\
\hline $\begin{array}{l}\text { U2AF35, } \\
\text { U2AF65, } \\
\text { ZRSR2, }\end{array}$ & Mutation & $\begin{array}{l}\text { Predicted to affect spliceosome assembly by } \\
\text { compromising function of spliceosome E/A } \\
\text { complexes }\end{array}$ & Myelodysplasia \\
\hline \multicolumn{4}{|l|}{ SFI, } \\
\hline \multicolumn{4}{|l|}{ PRPF40B ${ }^{48}$} \\
\hline PRPF3I, & & Predicted to affect spliceosome & \\
\hline PRPF8, & Mutation & $\begin{array}{l}\text { assembly by compromising function of tri-snRNPs } \\
\text { (U4/U6-U5) }\end{array}$ & Retinitis pigmentosa (RP) \\
\hline \multicolumn{4}{|l|}{ PRPF3, } \\
\hline \multicolumn{4}{|l|}{$\mathrm{PAPI}^{49}$} \\
\hline \multicolumn{4}{|c|}{ Defects in auxiliary splicing trans-factors } \\
\hline $\begin{array}{l}\text { TARDBP } \\
(\text { TDP-43) }\end{array}$ & Mutation & $\begin{array}{l}\text { Aberrant splicing regulations due to subcellular } \\
\text { mislocalization and cytoplasmic aggregates }\end{array}$ & $\begin{array}{l}\text { Amyotrophic lateral sclerosis (ALS), frontotemporal lobar } \\
\text { degeneration (FTLD), and Alzheimer's disease (AD) }\end{array}$ \\
\hline FUS/TLS 169,170 & Mutation & $\begin{array}{l}\text { Aberrant splicing regulations due to subcellular } \\
\text { mislocalization and cytoplasmic aggregates }\end{array}$ & ALS \\
\hline RBFOX ${ }^{171,172}$ & $\begin{array}{l}\text { Altered } \\
\text { expression }\end{array}$ & $\begin{array}{l}\text { Altered splicing and transcriptional networks in } \\
\text { neurons }\end{array}$ & Autism spectrum disorders (ASD) \\
\hline $\begin{array}{l}\text { hnRNPs } \\
\mathrm{A} 2 \mathrm{BI} \text { and } \\
\mathrm{Al}^{173}\end{array}$ & Mutation & $\begin{array}{l}\text { Altered dynamics of ribonucleoprotein granule } \\
\text { assembly and predicted to affect splicing }\end{array}$ & Multisystem proteinopathy, ALS \\
\hline HMGAIa ${ }^{67}$ & $\begin{array}{l}\text { Induced } \\
\text { expression }\end{array}$ & Aberrant skipping of exon 5 of PS2 & Sporadic AD \\
\hline GSK-3 $3^{63,64}$ & $\begin{array}{l}\text { Abnormal } \\
\text { expression }\end{array}$ & Aberrant splicing of exon 10 of tau gene & Tauopathies in neurodegenerative disorders, AD \\
\hline $\begin{array}{l}\text { NOVA- } \\
\left.\right|^{138,174,175}\end{array}$ & $\begin{array}{l}\text { Auto antibodies } \\
\text { against NOVA-I }\end{array}$ & $\begin{array}{l}\text { Aberrant splicing of NOVA-I-regulated pre-mRNAs } \\
\text { in neurons }\end{array}$ & Paraneoplastic syndrome \\
\hline hnRNP L 104 & Phosphorylation & Aberrant splicing of CASP9 & Tumorigenesis in non-small cell lung cancer \\
\hline QKI'103 & $\begin{array}{l}\text { Reduced } \\
\text { expression }\end{array}$ & Aberrant splicing of NUMB gene & Lung cancer \\
\hline SRSFI 98,99 & $\begin{array}{l}\text { Abnormal } \\
\text { expression }\end{array}$ & Aberrant splicing of SRSFI-regulated genes & Cancers \\
\hline SRSF3 $3^{101,102}$ & $\begin{array}{l}\text { Abnormal } \\
\text { expression }\end{array}$ & Aberrant splicing of SRSF3-regulated genes & Cancers \\
\hline
\end{tabular}


PSEN2 encoding the presenilin-2 (PS2) is one of Alzheimer's disease (AD)-associated genes. ${ }^{65}$ Aberrant skipping of exon 5 generates a truncated deleterious isoform (PS2V), which accumulates as visible PS2V bodies at high frequency in the hippocampus of sporadic AD patients. ${ }^{66}$ High mobility group A1 a protein (HMGA1a) had been demonstrated as a splicing regulator of PS2, which binds to a specific sequence in exon 5 preceding 5 ' splice site. ${ }^{67}$ Induced expression of HMGA1, observed in the brain of sporadic AD patients, result in aberrant skipping of PSEN2 exon 5, which is caused by an impaired dissociation of U1 snRNP from the 5' splice site. ${ }^{67,68}$

Recently, mutations in RBM20 gene have been shown to be associated with human dilated cardiomyopathy (DCM). ${ }^{69,70}$ Deep sequencing of the cardiac transcriptome revealed aberrant splicing of the titin gene (TTN). ${ }^{71}$ The detected aberrant TTN transcript was previously identified to be due to a loss-of-function mutation in RBM20 gene. ${ }^{69,70}$ Subsequent analysis revealed actual ciselements on TTN that are recognized by the splicing-suppressive RBM20. ${ }^{72}$ Transcriptome-wide RBM20-binding sites in heart were recently reported using photoactivatable ribonucleoside-enhanced crosslinking and immunoprecipitation (PAR-CLIP) followed by highthroughput sequencing of RNA. ${ }^{73}$ PAR-CLIP revealed that RBM20 regulates splicing of a network of genes with essential cardiac functions including TTN, RYR2, LMO7, RTN4, PDLIM3, CAMK2D, $L D B 3$, etc. Validation in patients with heart failure revealed that these genes were indeed aberrantly spliced in patients with severe heart failure who had low RBM20 expression levels in the heart. RBM20 thus plays an important role in modulation of cardiac functions and its defect predisposes to cardiomyopathy and heart failure.

\section{Nonsense-Associated Altered Splicing (NAS) and NMD-Associated Skipping of a Remote Exon (NASRE)}

Generation of a premature termination codon (PTC) sometimes causes skipping of a PTC-containing exon. This phenomenon is termed as NAS and a lot of such point mutations have been reported. For example, a nonsense mutation in exon 51 of $F B N 1$ gene, causes exon skipping which is associated with Marfan syndrome. ${ }^{74}$ NAS can be activated through different mechanisms. ${ }^{75}$ The most common one is nuclear scanning mechanism to ensure a proper translational frame. A nonsense mutation disrupting the open reading frame can direct the splicing machinery to skip the affected exon. This type of selective exon exclusion allows retention of the residual function of a protein instead of complete degradation by NMD. In case of an alternative exon, a nonsense mutation can cause an exclusive increase of exon-skipped transcripts due to the degradation of exon-included transcripts harboring a premature termination codon. In addition, a nonsense mutation can affect a local cis-element by disrupting an ESE or compromising an important element for RNA secondary structure, which subsequently promotes exon skipping. Mutation can also promote skipping of a remote exon not the PTC-bearing exon. In congenital myasthenic syndrome (CMS), we reported a $7 \mathrm{bp}$ deletion in CHRNE exon 7, which promotes skipping of the preceding exon $6 .{ }^{76}$ We termed this phenomenon as NASRE. Skipping of 101-nt exon 6 generates a PTC. Due to an inherent weak strength of splice sites flanking exon 6, CHRNE normally generates an exon 6-skipped transcript, which is completely degraded by NMD ${ }^{76}$ However, the 7 bp deletion in exon 7 resumes an open reading frame in the exon 6-skipped transcript, which makes the exon 6-skipped transcript immune to NMD. Remote exon skipping is also evident in other genes, such as $S L C 25 A 20,{ }^{77} D B T,{ }^{78} B T K,{ }^{79} M L H 1,{ }^{80}$ etc. However, NASRE is likely to be underestimated because remote exons are seldom scrutinized in investigating human diseases.

\section{Trans-Dominant splicing defects due to cis-acting repeat expansions}

An unusual mode of splicing defect arises from abnormal expansion of unstable nucleotide repeats in transcribed genomic regions. Pathogenic expanded repeats can affect splicing in two ways. First, repeat expansion in the coding region can alter the function of an encoded protein, either by loss of normal functions or gain of aberrant functions. Such type of misregulations have been observed in spinocerebellar ataxias, Huntington diseases, and oculopharyngeal muscular dystrophy. ${ }^{81}$ Second, repeat expansion in a non-coding region gains an aberrant function in RNA itself. A remarkable example of this type of disease is myotonic dystrophy (DM), caused by a CTG-repeat expansion in the 3' UTR of DMPK (DM1), or by CCTG-repeat expansion in the first intron of ZNF9 (DM2). RNA containing expanded CUG- or CCUG-repeats forms a double-stranded RNA structure and accumulate in nuclear foci, which subsequently sequesters an important splicing regulator, MBNL1. Therefore, MBNL1 is depleted from nucleoplasm, resulting in a loss of MBNL1 function. ${ }^{82,83}$ Expanded CUG- and CCUG-repeats concurrently induce the stability of another splicing regulator CUGBP $1,{ }^{84}$ although the mechanisms are not fully elucidated yet. As a consequence, numerous alterations in splicing regulations occur in different genes including chloride channel (CLCN1), bridging integrator 1 (BIN1), insulin receptor (INSR), etc. in DM tissues..$^{81,85}$ Other examples of unstable repeat expansion-related diseases are discussed in details in other review articles. ${ }^{81,86}$

\section{Misregulated splicing in cancers}

Deregulated splicing events have been demonstrated in almost all kinds of cancers. Aberrant splicing affects numerous processes of cancer development and progression including cell cycle control, initiation, invasion, metastasis, apoptosis, cellular metabolism, cellular signaling, etc. ${ }^{87}$ Cancer cells exploit the plasticity of alternative splicing to generate aberrant proteins to support development and progression of cancer cells. Cancer-associated missplicing can result from alterations in multiple physiological splicing processes. The affected processes include cis-acting splicing defects in oncogenes, tumor suppressors and any other genes related to cancers; defects in splicing trans-factors including a loss of function, a gain of aberrant function, abnormal expression, subcellular mislocalization, and altered post-translational modification; and a change in cellular environment that regulates alternative splicing. Cancer-associated cisacting splicing defects have been reported in many genes. A notable example is $B R C A 1$, where germline mutations are predisposed to breast and ovarian cancers. An inherited ESE-disrupting mutation in exon 18 was initially reported to cause aberrant exon skipping. ${ }^{88} \mathrm{~A}$ large $N U M B$ er of mutations affecting splicing regulatory cis-elements have been reported later in $B R C A 1{ }^{89-91}$ Other remarkable cis-acting splicing defects associated with cancers are found in $K L F 6, C D H 17$, $K I T$, and LKB1, which are discussed in detail in a relevant review article. $^{92}$

trans-acting splicing defects in cancers were initially characterized in family of hnRNPs and SR proteins. A noteworthy example is hnRNP A/B family consisting of hnRNPs A1, A2, and A3. Among the members, hnRNPs A1 and A2 are significantly over expressed in a variety of cancers. ${ }^{93-95}$ Depletion of hnRNP A1 and hnRNP A2 causes apoptosis in cancer cells, but not in normal cells, indicating a clear association of these proteins in development of cancer. ${ }^{94} \mathrm{~A}$ deeply dissected splicing target of both hnRNP A1 and A2 is the PKM gene encoding pyruvate kinase. Splicing misregulation of $P K M$ critically 
affects glucose metabolism in tumor cells. Mechanistic investigation demonstrated that hnRNPs A1 and A2 along with another member of hnRNP family, PTB, bind to the PKM gene in a sequence specific manner flanking exon 9 and subsequently regulate mutual splicing of exon 9 and exon 10 to generate two spliced isoforms of $P K M 1$ and $P K M 2 .{ }^{93}$ Analysis of expression level in normal and glioma samples demonstrated that the ratio of $P K M 2 / P K M 1$ is significantly correlated with the level of hnRNPs A1, A2, and PTB. Depletion of these transfactors, as well as MYC, which is a modulator of their expressions, induces a switch from $P K M 2$ to $P K M 1 .{ }^{93}$ The association of PTB is also reported in ovarian cancer. ${ }^{96}$ Another member hnRNP $\mathrm{H}$ has also been reported to be associated with cancer, which regulates splicing aberration of $I G 20 / M A D D$ and $R O N$ pre-mRNAs. ${ }^{97}$

Among the SR proteins, SRSF1 is the best characterized cancerassociated factor. A lot of cancer-associated missplicing events regulated by SRSF1 have been reported to date. For example, SRSF 1 binds to an ESE in RON exon 12 and promotes exon skipping to generate a functionally altered truncated protein inducing cancer invasions. ${ }^{98}$ Another example is $B I N 1$, which is a tumor suppressor gene. Induced expression of SRSF1 promotes inclusion of exon 12a, and generates an isoform lacking a tumor suppressing activity. ${ }^{99}$ In addition, over expression of SRSF1 induces generation of an isoform MNK2b from MNK2 pre-mRNA and promotes MAPK-independent phosphorylation of eIF4E, leading to oncogenic transformation. ${ }^{99}$ Another SR protein, SRSF3 is also altered in numerous cancers SRSF3 has been reported to be over expressed in numerous human cancers including cervical, lung, breast, liver, thyroid, stomach, skin, bladder, kidney and colon cancers ${ }^{100}$ SRSF3 regulatesp53-mediated cellular senescence to suppress tumorigenesis, through alternative splicing of TP53. ${ }^{101}$ Mechanistic analysis revealed that SRSF3 binds to exon i9 of TP53 and prevents its inclusion in its pre-mRNA splicing. ${ }^{101}$ SRSF3 also regulates alternative splicing of exon 10 of $P K M$ gene by binding to an ESE in exon 10 thereby affecting lactate production, which is critically associated with cancer. ${ }^{102}$

In addition to hnRNPs and SR proteins, other splicing regulatory proteins are also involved in cancers. For example, an RNA-binding protein, Quaking (QKI), has been identified as a key regulator of alternative splicing in lung cancer. Down-regulation of QKI expression has been demonstrated in lung cancer, which is significantly correlated with poor prognosis. ${ }^{103}$ QKI-5, a splice variant of QKI, inhibits cancer cell proliferation and prevents inappropriate activation of the Notch signaling pathway by regulating pre-mRNA splicing of a key regulatory gene $N U M B .{ }^{103}$ Investigation of underlying mechanisms demonstrated that QKI-5 recognizes two cis-elements in NUMB premRNA and suppresses inclusion of exon 12 by competing with the core spliceosome component SF1. As a result, an exon 12-excluded $N U M B$ isoform is generated, which is unable to activate the Notch signaling pathway.
Post-translational modifications of splicing factors sometimes critically affect their functions and are also documented in cancers. A striking example is hnRNP L, which regulates tumorigenesis in lung cancer by modulating pre-mRNA splicing of $C A S P 9$ encoding caspase 9. ${ }^{104}$ Alternative splicing of CASP9 generates two variants: a long variant $9 \mathrm{a}$ and a short variant $9 \mathrm{~b}$ lacking four exons. A short variant $9 \mathrm{~b}$ is deficient for apoptotic function compared to $9 \mathrm{a}$. In addition $9 \mathrm{~b}$ competitively inhibits the activation of 9a. HnRNP L is a critical splicing suppressor in non-small cell lung cancers (NSCLS), which functions by binding to an exonic splicing silencer to generate caspase $9 b .{ }^{104}$ However, the splicing modulation by hnRNP L is not evident in non-transformed cells, suggesting a potential post-translational modification of hnRNP L specific to NSCLS. Further analysis indeed revealed the phosphorylation of a serine residue $\left(\mathrm{Ser}^{55}\right)$ of hnRNP $\mathrm{L}$, which is critical to regulate CASP9 pre-mRNA splicing for the tumorigenic capacity of NSCLS cells. ${ }^{104}$

\section{Web based in silico programs to analyze splicing code}

With the progress of splicing researches, a lot of in Silico programs have been developed to assess alternative splicing isoforms, cis-acting splicing code, effects of mutations on splicing, predicting functional splicing regulatory motifs and their cognate partner, strength of splice sites, RNA secondary structure, etc. We have enlisted popular programs in Table 4. We also developed an algorithm in order to uncover underestimated splicing effects due to exonic mutations at the 5 ' splice site. ${ }^{105}$ For this purpose, we initially constructed 31 minigenes spanning exonic splicing mutations and analyzed the splicing consequences using splicing RT-PCR. We also scrutinized 189, 249 U2-dependent 5' splice sites of the entire human genome. As a prediction parameter, we set out a new variable called the SD-Score, which represents a common logarithm of the frequency of a specific 5 ' splice site spanning 9 nucleotides (3 nucleotides at the 3' end of an exon and 6 nucleotides at the 5' end of an intron). Our analysis demonstrated that SD-Score can efficiently predict the splicing consequences of these minigenes. In order to improve the prediction accuracy, we further employed the information contents (Ri). In an attempt to validate our algorithm, we scrutinized 32 additional minigenes as well as 179 previously reported splicing mutations. As an estimate, the SD-Score algorithm predicted aberrant splicing in 198 of 204 sites with a sensitivity of $97.1 \%$ and normal splicing in 36 of 38 sites with a specificity of $94.7 \%$. An extensive simulation of all possible exonic mutations at positions $-3,-2$ and -1 at 189 , 2495 ' splice sites predicted aberration of pre-mRNA splicing in $37.8 \%, 88.8 \%$ and $96.8 \%$ of simulated mutations, respectively, which were all higher than we expected. Although in Silico programs are playing great roles in identifying splicing cis-elements in normal and pathological conditions, no programs have $100 \%$ accuracy. Therefore, in vitro and/or in vivo investigations of individual genes, along with in Silico analysis, are indispensable for elucidation of normal and pathological splicing regulations.

Table 4 Databases and web-based programs for analyzing splicing mutations and alternative splicing

\begin{tabular}{|c|c|c|}
\hline Program & URL & Feature \\
\hline \multicolumn{3}{|c|}{ Database of alternative splicing events } \\
\hline $\begin{array}{l}\text { Alternative splicing } \\
\text { Database }^{176}\end{array}$ & http://cgsigma.cshl.org/new_alt_exon_db2/ & A database of alternative splicing based on published reports \\
\hline $\mathrm{ASPicDB}^{177}$ & http://www.caspur.it/ASPicDB/ & An annotation-based database of alternative transcript and protein isoforms \\
\hline
\end{tabular}

Database of mutations and other genetic variations

HGMD $^{178} \quad$ http://www.hgmd.org/

A database of human gene mutations associated with inherited diseases 
Table continued...

\begin{tabular}{lll}
\hline Program & URL & Feature \\
\hline ssSNP Target ${ }^{179}$ & http://ssSNPTarget.org/ & A database for single nucleotide polymorphisms \\
dbSNP180 & http://www.ncbi.nlm.nih.gov/SNP/ & A comprehensive database of SNPs \\
I000 genome & http://browser.1000genomes.org/ & I000 genome project \\
NHLBI ESP & http://evs.gs.washington.edu/EVS/ & NHLBI exome sequencing project \\
HGVD 182 & http://www.genome.med.kyoto-u.ac.jp/ & Human genetic variation database (HGVD)
\end{tabular}

Tools to evaluate splice sites (5' splice site, 3' splice site, and branch point)

Human Splicing

Finder $^{183}$

http://www.umd.be/HSF/

SD score ${ }^{105}$

MaxEntScan ${ }^{184}$

Analyzer Splice

Tool (AST) $)^{185,186}$

DBASS5 ${ }^{187}$

DBASS3 $3^{187}$

Splicing regulatory elements and splicing factors assessment tools

\begin{tabular}{|c|c|}
\hline Splice Aid ${ }^{188}$ & http://www.introni.it/splicing.html \\
\hline SpliceAid2 ${ }^{189}$ & www.introni.it/spliceaid.html \\
\hline ESE finder ${ }^{190,191}$ & $\begin{array}{l}\text { http://rulai.cshl.edu/cgi-bin/tools/ESE3/ } \\
\text { esefinder.cgi?process=homeb }\end{array}$ \\
\hline Rescue-ESE ${ }^{192,193}$ & http://genes.mit.edu/burgelab/rescue-ese/ \\
\hline FAS-ESS ${ }^{194}$ & http://genes.mit.edu/fas-ess/ \\
\hline SFmap ${ }^{195}$ & http://sfmap.technion.ac.il \\
\hline \multicolumn{2}{|c|}{ RNA secondary structure assessment tools } \\
\hline mFold ${ }^{196}$ & $\begin{array}{l}\text { http://www.bioinfo.rpi.edu/applications/ } \\
\text { mfold/rna/form l.cgi/ }\end{array}$ \\
\hline sFold ${ }^{197}$ & http://sfold.wadsworth.org/ \\
\hline pFold ${ }^{198}$ & http://www.daimi.au.dk/ compbio/pfold/ \\
\hline
\end{tabular}

\section{Conclusion}

Analyses of abnormal splicing code in human diseases not only uncover the underlying maladies of splicing regulation in pathological conditions, but also allow us to obtain an insight in splicing controls in physiological conditions. The advances in research on splicing aberrations in numerous diseases also provide us knowledge to identify mutations that had been otherwise difficult to ascertain. In addition, understanding physiological and pathological splicing mechanisms also paves the way for development of therapeutic strategies. We have shown that the complex and intricate nature of alternative splicing events confers the transcriptome and proteome diversity and facilitates biologically beneficial processes including molecular evolution. The complex and intricate nature, however ironically makes alternative splicing highly susceptible to deleterious malfunctions causing diseases. For a particular splicing defect in a particular pathological condition, elucidation of the underlying
A tool to evaluate the splicing effect of a mutation and to identify splicing motifs in human sequences

A tool to predict the effect of a mutation at 5' splice site

A tool to score authentic and possible splice sites in a given sequence with different models

An algorithm to calculate the scores of donor and acceptor sequences

A database for 5' splice site aberration

A database for 3' splice site aberration

A database of experimentally proven RNA target motifs bound by splicing proteins in humans

A database of tissue-specific human splicing factors and RNA target motifs

A tool to identify exonic splicing enhancers

A tool for identifying candidate ESEs in vertebrate exons

A tool to predict ESS motifs

A tool for motif analysis and prediction of splicing factors

A tool to predict the secondary structure of single stranded nucleic acids

A tool to predict RNA secondary structure, andfor the rational design of RNA-targeting nucleic acids

RNA secondary structure prediction tool using stochastic context-free grammars

misregulation enables us to estimate if the splicing defect is a direct cause or an indirect modifier in the process of disease development. Elucidation of the underlying mechanisms of splicing perturbations also tells us potential therapeutic targets such as RNAs, RNPs, and auxiliary associated factors. By modulating these targets, we may be able to reverse the aberrant splicing to a physiological state. Evidently, advances in molecular targeting therapy for alternative splicing are growing at a steady pace and are moving forward from the laboratory bench to the clinic.

\section{Acknowledgements}

The works performed in our laboratory were supported by Grantsin-Aid from the MEXT and MHLW of Japan.

\section{Conflict of interest}

Author declares that there is no conflict of interest. 


\section{References}

1. Pan Q, Shai O, Lee LJ, et al. Deep surveying of alternative splicing complexity in the human transcriptome by high-throughput sequencing. Nat Genet. 2008;40(12):1413-1415.

2. Wang ET, Sandberg R, Luo S, et al. Alternative isoform regulation in human tissue transcriptomes. Nature. 2008;456(7221):470-476.

3. Graveley BR. Sorting out the complexity of SR protein functions. $R N A$. 2000;6(9):1197-1211.

4. Lin $\mathrm{S}, \mathrm{Fu} \mathrm{XD}$. SR proteins and related factors in alternative splicing. $A d v$ Exp Med Biol. 2007;623:107-122.

5. Shen H, Green MR. A pathway of sequential arginine-serine-rich domain-splicing signal interactions during mammalian spliceosome assembly. Mol Cell. 2004;16(3):363-373.

6. Shen HH, Kan JLC, Green MR. Arginine-serine-rich domains bound at splicing enhancers contact the branchpoint to promote prespliceosome assembly. Mol Cell. 2004;13(3):367-376.

7. Martinez-Contreras R, Cloutier P, Shkreta L, et al. hnRNP proteins and splicing control. Adv Exp Med Biol. 2007;623:123-147.

8. Wang Y, Ma M, Xiao X, et al. Intronic splicing enhancers, cognate splicing factors and context-dependent regulation rules. Nat Struct Mol Biol. 2012;19(10):1044-1052.

9. Mauger DM, Lin C, Garcia-Blanco MA. hnRNP H and hnRNP F complex with Fox 2 to silence fibroblast growth factor receptor 2 exon IIIc. Mol Cell Biol. 2008;28(17):5403-5419.

10. Ule J, Stefani G, Mele A, et al. An RNA map predicting Nova-dependent splicing regulation. Nature. 2006;444(7119):580-586.

11. Yeo GW, Coufal NG, Liang TY, et al. An RNA code for the FOX2 splicing regulator revealed by mapping RNA-protein interactions in stem cells. Nat Struct Mol Biol. 2009;16(2):130-137.

12. Wahl MC, Will CL, Luhrmann R. The spliceosome: design principles of a dynamic RNP machine. Cell. 2009;136(4):701-718.

13. House AE, Lynch KW. Regulation of alternative splicing: More than just the ABCs. J Biol Chem. 2008;283(3):1217-1221.

14. Schneider M, Will CL, Anokhina M, et al. Exon Definition Complexes Contain the Tri-snRNP and Can Be Directly Converted into B-like Precatalytic Splicing Complexes. Mol Cell. 2010;38(2):223-235.

15. Matlin AJ, Clark F, Smith CW. Understanding alternative splicing: towards a cellular code. Nat Rev Mol Cell Biol. 2005;6(5):386-398.

16. Hitti E, Khabar KS. Sequence variations affecting AU-rich element function and disease. Front Biosci (Landmark Ed). 2012;17:1846-1860.

17. Lerner MR, Boyle JA, Mount SM, et al. Are snRNPs involved in splicing? Nature. 1980;283(5743):220-224.

18. Roca X, Krainer AR. Recognition of atypical 5' splice sites by shifted base-pairing to U1 snRNA. Nat Struct Mol Biol. 2009;16(2):176-182.

19. Langford CJ, Gallwitz D. Evidence for an intron-contained sequence required for the splicing of yeast RNA polymerase II transcripts. Cell. 1983;33(2):519-527.

20. Gao K, Masuda A, Matsuura T, et al. Human branch point consensus sequence is yUnAy. Nucleic Acids Res. 2008;36(7):2257-2267.

21. Taggart AJ, DeSimone AM, Shih JS, et al. Large-scale mapping of branchpoints in human pre-mRNA transcripts in vivo. Nat Struct Mol Biol. 2012;19(7):719-721.

22. Bitton DA, Rallis C, Jeffares DC, et al. LaSSO, a strategy for genomewide mapping of intronic lariats and branch points using RNA-seq. Genome Res. 2014;24(7):1169-1179.
23. Coolidge CJ, Seely RJ, Patton JG. Functional analysis of the polypyrimidine tract in pre-mRNA splicing. Nucleic Acids Res. 1997;25(4):888-896.

24. Mullen MP, Smith CW, Patton JG, et al. Alpha-tropomyosin mutually exclusive exon selection: competition between branchpoint/ polypyrimidine tracts determines default exon choice. Genes Dev. 1991;5(4):642-655.

25. Fu Y, Masuda A, Ito M, et al. AG-dependent 3'-splice sites are predisposed to aberrant splicing due to a mutation at the first nucleotide of an exon. Nucleic Acids Res. 2011;39(10):4396-4404.

26. Wu S, Romfo CM, Nilsen $\mathrm{TW}$, et al. Functional recognition of the 3' splice site $A G$ by the splicing factor U2AF35. Nature. 1999;402(6763):832-835.

27. Masuda A, Shen XM, Ito M, et al. hnRNP H enhances skipping of a nonfunctional exon P3A in CHRNA1 and a mutation disrupting its binding causes congenital myasthenic syndrome. Hum Mol Genet. 2008;17(24):4022-4035.

28. Cartegni L, Krainer AR. Disruption of an SF2/ASF-dependent exonic splicing enhancer in SMN2 causes spinal muscular atrophy in the absence of SMN1. Nat Genet. 2002;30(4):377-384.

29. Cartegni L, Hastings ML, Calarco JA, et al. Determinants of exon 7 splicing in the spinal muscular atrophy genes, SMN1 and SMN2. Am J Hum Genet. 2006;78(1):63-77.

30. Kashima T, Manley JL. A negative element in SMN2 exon 7 inhibits splicing in spinal muscular atrophy. Nat Genet. 2003;34(4):460-463.

31. Kashima T, Rao N, David CJ, et al. hnRNP A1 functions with specificity in repression of SMN2 exon 7 splicing. Hum Mol Genet. 2007;16(24):3149-3159.

32. Rahman MA, Masuda A, Ohe K, et al. HnRNP L and hnRNP LL antagonistically modulate PTB-mediated splicing suppression of CHRNA1 pre-mRNA. Sci Rep. 2013;3:2931.

33. Nasrin F, Rahman MA, Masuda A, et al. HnRNP C, YB-1 and hnRNP L coordinately enhance skipping of human MUSK exon 10 to generate a Wnt-insensitive MuSK isoform. Sci Rep. 2014;4:6841.

34. Eperon LP, Graham IR, Griffiths AD, et al. Effects of RNA secondary structure on alternative splicing of pre-mRNA: is folding limited to a region behind the transcribing RNA polymerase? Cell. 1988;54(3):393-401.

35. Graveley BR. Mutually exclusive splicing of the insect Dscam premRNA directed by competing intronic RNA secondary structures. Cell. 2005;123(1):65-73.

36. Hiller M, Zhang Z, Backofen R, et al. Pre-mRNA secondary structures influence exon recognition. PLoS Genet. 2007;3(11):e204.

37. Lovci MT, Ghanem D, Marr H, et al. Rbfox proteins regulate alternative mRNA splicing through evolutionarily conserved RNA bridges. Nat Struct Mol Biol. 2013;20(12):1434-1442.

38. Grover A, Houlden H, Baker M, et al. 5' splice site mutations in tau associated with the inherited dementia FTDP-17 affect a stem-loop structure that regulates alternative splicing of exon 10. J Biol Chem. 1999;274(21):15134-15143.

39. Jiang Z, Cote J, Kwon JM, et al. Aberrant splicing of tau pre-mRNA caused by intronic mutations associated with the inherited dementia frontotemporal dementia with parkinsonism linked to chromosome 17 . Mol Cell Biol. 2000;20(11):4036-4048.

40. Varani L, Hasegawa M, Spillantini MG, et al. Structure of tau exon 10 splicing regulatory element RNA and destabilization by mutations of frontotemporal dementia and parkinsonism linked to chromosome 17. Proc Natl Acad Sci U S A. 1999;96(14):8229-8234. 
41. Yasuda M, Takamatsu J, D'Souza I, et al. A novel mutation at position+12 in the intron following exon 10 of the tau gene in familial frontotemporal dementia (FTD-Kumamoto). Ann Neurol. 2000;47(4):422-429.

42. Dhir A, Buratti E. Alternative splicing: role of pseudoexons in human disease and potential therapeutic strategies. FEBS $J$ 2010;277(4):841-855

43. Madden HR, Fletcher S, Davis MR, et al. Characterization of a complex Duchenne muscular dystrophy-causing dystrophin gene inversion and restoration of the reading frame by induced exon skipping. Hum Mutat. 2009;30(1):22-28

44. Vorechovsky I. Transposable elements in disease-associated cryptic exons. Hum Genet. 2010;127(2):135-154

45. Ikeda TM, Kobayashi K, Kanagawa M, et al. Pathogenic exon-trapping by SVA retrotransposon and rescue in Fukuyama muscular dystrophy. Nature. 2011;478(7367):127-131.

46. Krull M, Petrusma M, Makalowski W, et al. Functional persistence of exonized mammalian-wide interspersed repeat elements (MIRs) Genome Res. 2007;17(8):1139-1145.

47. Guyon T, Levasseur P, Truffault F, et al. Regulation of AcetylcholineReceptor Alpha-Subunit Variants in Human Myasthenia-Gravis. Quantification of Steady-State Levels of Messenger-RNA in Muscle biopsy using the Polymerase Chain-Reaction. J Clin Invest. 1994;94(1):16-24.

48. Yoshida K, Sanada M, Shiraishi Y, et al. Frequent pathway mutations of splicing machinery in myelodysplasia. Nature. 2011;478(7367):64-69.

49. Mordes D, Luo X, Kar A, et al. Pre-mRNA splicing and retinitis pigmentosa. Mol Vis 2006;12:1259-1271.

50. Zhang Z, Lotti F, Dittmar K, et al. SMN deficiency causes tissue-specific perturbations in the repertoire of snRNAs and widespread defects in splicing. Cell. 2008;133(4):585-600.

51. Kabashi E, Valdmanis PN, Dion P, et al. TARDBP mutations in individuals with sporadic and familial amyotrophic lateral sclerosis. Nat Genet. 2008;40(5):572-574.

52. Rutherford NJ, Zhang YJ, Baker M, et al. Novel Mutations in TARDBP(TDP-43) in Patients with Familial Amyotrophic Lateral Sclerosis. PLoS Genet. 2008;4(9):e1000193.

53. Sreedharan J, Blair IP, Tripathi VB, et al. TDP-43 mutations in familial and sporadic amyotrophic lateral sclerosis. Science. 2008;319(5870):1668-1672.

54. Buratti E, Dork T, Zuccato E, et al. Nuclear factor TDP-43 and SR proteins promote in vitro and in vivo CFTR exon 9 skipping. EMBO J. 2001;20(7):1774-1784.

55. Chu CS, Trapnell BC, Curristin S, et al. Genetic-Basis of Variable Exon9 Skipping in Cystic-Fibrosis transmembrane Conductance Regulator Messenger-RNA. Nat Genet. 1993;3(2):151-156.

56. Cuppens H, Lin W, Jaspers M, et al. Polyvariant mutant cystic fibrosis transmembrane conductance regulator genes. The polymorphic (Tg) $\mathrm{m}$ locus explains the partial penetrance of the T5 polymorphism as a disease mutation. J Clin Invest. 1998;101(2):487-496.

57. Polymenidou M, Tourenne CL, Hutt KR, et al. Long pre-mRNA depletion and RNA missplicing contribute to neuronal vulnerability from loss of TDP-43. Nat Neurosci. 2011;14(4):459-468.

58. Tollervey JR, Curk T, Rogelj B, et al. Characterizing the RNA targets and position-dependent splicing regulation by TDP-43. Nat Neurosci. 2011;14(4):452-458.

59. Alami NH, Smith RB, Carrasco MA, et al. Axonal transport of TDP43 mRNA granules is impaired by ALS-causing mutations. Neuron. 2014;81(3):536-543.
60. Arai T, Hasegawa M, Akiyama $\mathrm{H}$, et al. TDP-43 is a component of ubiquitin-positive tau-negative inclusions in frontotemporal lobar degeneration and amyotrophic lateral sclerosis. Biochem Biophys Res Commun. 2006;351(3):602-611.

61. Neumann M, Sampathu DM, Kwong LK, et al. Ubiquitinated TDP-43 in frontotemporal lobar degeneration and amyotrophic lateral sclerosis. Science. 2006;314(5796):130-133.

62. Freibaum BD, Chitta RK, High AA, et al. Global Analysis of TDP-43 Interacting Proteins Reveals Strong Association with RNA Splicing and Translation Machinery. J Proteome Res. 2010;9(2):1104-1120.

63. Hernandez F, Perez M, Lucas JJ, et al. Glycogen synthase kinase-3 plays a crucial role in tau exon 10 splicing and intranuclear distribution of SC35. Implications for Alzheimer's disease. $J$ Biol Chem. 2004;279(5):3801-3806.

64. Hanger DP, Noble W. Functional implications of glycogen synthase kinase-3-mediated tau phosphorylation. Int $J$ Alzheimers Dis. 2011;2011:352805.

65. St George-Hyslop PH, Petit A. Molecular biology and genetics of Alzheimer's disease. C R Biol. 2005;328(2):119-130.

66. Sato N, Hori O, Yamaguchi A, et al. A novel presenilin-2 splice variant in human Alzheimer's disease brain tissue. $J$ Neurochem. 1999;72(6):2498-2505.

67. Manabe T, Katayama T, Sato N, et al. Induced HMGA1a expression causes aberrant splicing of Presenilin-2 pre-mRNA in sporadic Alzheimer's disease. Cell Death Differ. 2003;10(6):698-708.

68. Ohe K, Mayeda A. HMGA1a trapping of U1 snRNP at an authentic 5 ' splice site induces aberrant exon skipping in sporadic Alzheimer's disease. Mol Cell Biol. 2010;30(9):2220-2228.

69. Brauch KM, Karst ML, Herron KJ, et al. Mutations in Ribonucleic Acid Binding Protein Gene Cause Familial Dilated Cardiomyopathy. J Am Coll Cardiol. 2009;54(10):930-941.

70. Li DX, Morales A, Quintana JG, et al. Identification of Novel Mutations in RBM20 in Patients with dilated cardiomyopathy. Clin Transl Sci. 2010;3(3):90-97.

71. Guo W, Schafer S, Greaser ML, et al. RBM20, a gene for hereditary cardiomyopathy, regulates titin splicing. Nat Med. 2012;18(5):766-773.

72. Li SJ, Guo W, Dewey CN, et al. Rbm 20 regulates titin alternative splicing as a splicing repressor. Nucleic Acids Res. 2013;41(4):2659-2672.

73. Maatz H, Jens M, Liss M, et al. RNA-binding protein RBM20 represses splicing to orchestrate cardiac pre-mRNA processing. $J$ Clin Invest. 2014;124(8):3419-3430.

74. Dietz HC, Valle D, Francomano CA, et al. The skipping of constitutive exons in vivo induced by nonsense mutations. Science. 1993;259(5095):680-683.

75. Cartegni L, Chew SL, Krainer AR. Listening to silence and understanding nonsense: Exonic mutations that affect splicing. Nat Rev Genet. 2002;3(4):285-298.

76. Ohno K, Milone M, Shen XM, et al. A frameshifting mutation in CHRNE unmasks skipping of the preceding exon. Hum Mol Genet. 2003;12(23):3055-3066

77. Hsu BY, Iacobazzi V, Wang Z, et al. Aberrant mRNA splicing associated with coding region mutations in children with carnitine-acylcarnitine translocase deficiency. Mol Genet Metab. 2001;74(1-2):248-255.

78. Fisher CW, Fisher CR, Chuang JL, et al. Occurrence of a 2-Bp (at) Deletion Allele and a Nonsense (G-to-T) Mutant Allele at the E2 (Dbt) Locus of 6 Patients with Maple Syrup Urine Disease - Multiple-Exon Skipping as a Secondary Effect of the Mutations. Am J Hum Genet. $1993 ; 52(2): 414-424$ 
79. Haire RN, Ohta Y, Strong SJ, et al. Unusual patterns of exon skipping in Bruton tyrosine kinase are associated with mutations involving the intron 17 3' splice site. Am J Hum Genet. 1997;60(4):798-807.

80. Clarke LA, Veiga I, Isidro G, et al. Pathological exon skipping in an HNPCC proband with MLH1 splice acceptor site mutation. Genes Chromosomes Cancer. 2000;29(4):367-370.

81. Gatchel JR, Zoghbi HY. Diseases of unstable repeat expansion: Mechanisms and common principles. Nat Rev Genet.

1. $2005 ; 6(10): 743-755$.

82. Davis BM, McCurrach ME, Taneja KL, et al. Expansion of a CUG trinucleotide repeat in the 3' untranslated region of myotonic dystrophy protein kinase transcripts results in nuclear retention of transcripts. Proc Natl Acad Sci U S A. 1997;94(14):7388-7393.

83. Lin XY, Miller JW, Mankodi A, et al. Failure of MBNL1-dependent post-natal splicing transitions in myotonic dystrophy. Hum Mol Genet. 2006;15(13):2087-2097.

84. Dansithong W, Paul S, Comai L, et al. MBNL1 is the primary determinant of focus formation and aberrant insulin receptor splicing in DM1. J Biol Chem. 2005;280(7):5773-5780.

85. Fugier C, Klein AF, Hammer C, et al. Misregulated alternative splicing of BIN1 is associated with T tubule alterations and muscle weakness in myotonic dystrophy. Nat Med. 2011;17(6):720-725.

86. Nelson DL, Orr HT, Warren ST. The unstable repeats--three evolving faces of neurological disease. Neuron. 2013;77(5):825-843.

87. David CJ, Manley JL.Alternative pre-mRNAsplicing regulation in cancer: pathways and programs unhinged. Genes Dev. 2010;24(21):2343-2364.

88. Mazoyer S, Puget N, Vidoz LP, et al. A BRCA1 nonsense mutation causes exon skipping. Am J Hum Genet. 1998;62(3):713-715.

89. Wappenschmidt B, Becker AA, Hauke J, et al. Analysis of 30 Putative BRCA1 Splicing Mutations in Hereditary Breast and Ovarian Cancer Families Identifies Exonic Splice Site Mutations That Escape in Silico Prediction. PLoS One. 2012;7(12):e50800.

90. Sanz DJ, Acedo A, Infante M, et al. A High Proportion of DNA Variants of BRCA1 and BRCA2 Is Associated with Aberrant Splicing in Breast/ Ovarian Cancer Patients. Clin Cancer Res. 2010;16(6):1957-1967.

91. Bonnet C, Krieger S, Vezain M, et al. Screening BRCA1 and BRCA2 unclassified variants for splicing mutations using reverse transcription PCR on patient RNA and an ex vivo assay based on a splicing reporter minigene. J Med Genet. 2008;45(7):438-446.

92. Srebrow A, Kornblihtt AR. The connection between splicing and cancer. J Cell Sci. 2006;119(13):2635-2641.

93. David CJ, Chen M, Assanah M, et al. HnRNP proteins controlled by c-Myc deregulate pyruvate kinase mRNA splicing in cancer. Nature 2010;463(7279):364-368.

94. Patry C, Bouchard L, Labrecque P, et al. Small interfering RNA-mediated reduction in heterogeneous nuclear ribonucleoparticule $\mathrm{A} 1 / \mathrm{A} 2$ proteins induces apoptosis in human cancer cells but not in normal mortal cell lines. Cancer Res. 2003;63(22):7679-7688.

95. Gerstl GR, Cohen M, Shilo A, et al. Splicing factor hnRNP A2/B1 regulates tumor suppressor gene splicing and is an oncogenic driver in glioblastoma. Cancer Res. 2011;71(13):4464-4472.

96. He X, Pool M, Darcy KM, et al. Knockdown of polypyrimidine tractbinding protein suppresses ovarian tumor cell growth and invasiveness in vitro. Oncogene. 2007;26(34):4961-4968.

97. Lefave CV, Squatrito M, Vorlova S, et al. Splicing factor hnRNPH drives an oncogenic splicing switch in gliomas. EMBO J. 2011;30(19):4084-4097.
98. Ghigna C, Giordano S, Shen HH, et al. Cell motility is controlled by SF2/ASF through alternative splicing of the Ron protooncogene. Mol Cell. 2005;20(6):881-890.

99. Karni R, de Stanchina E, Lowe SW, et al. The gene encoding the splicing factor SF2/ASF is a proto-oncogene. Nat Struct Mol Biol. 2007;14(3):185-193.

100. Jia R, Li CL, Mccoy JP, et al. SRp20 is a proto-oncogene critical for cell proliferation and tumor induction and maintenance. Int J Biol Sci. 2010;6(7):806-826.

101. Tang Y, Horikawa I, Ajiro M, et al. Downregulation of splicing factor SRSF3 induces p53 beta, an alternatively spliced isoform of p53 that promotes cellular senescence. Oncogene. 2013;32(22):2792-2798.

102. Wang Z, Chatterjee D, Jeon HY, et al. Exon-centric regulation of pyruvate kinase $\mathrm{M}$ alternative splicing via mutually exclusive exons. $J$ Mol Cell Biol. 2012;4(2):79-87.

103. Zong FY, Fu X, Wei WJ, et al. The RNA-Binding Protein QKI Suppresses Cancer-Associated Aberrant Splicing. PLoS Genet. 2014;10(4):e1004289.

104. Goehe RW, Shultz JC, Murudkar C, et al. hnRNP L regulates the tumorigenic capacity of lung cancer xenografts in mice via caspase-9 pre-mRNA processing. J Clin Invest. 2010;120(11):3923-3939.

105. Sahashi K, Masuda A, Matsuura T, et al. In vitro and in Silico analysis reveals an efficient algorithm to predict the splicing consequences of mutations at the 5' splice sites. Nucleic Acids Res. 2007;35(18):5995-6003.

106. Liu HX, Zhang M, Krainer AR. Identification of functional exonic splicing enhancer motifs recognized by individual SR proteins. Genes Dev. 1998;12(13):1998-2012.

107. Tacke R, Manley JL. The human splicing factors ASF/SF2 and SC35 possess distinct, functionally significant RNA binding specificities. EMBO J. 1995;14(14):3540-3551.

108. Pandit S, Zhou Y, Shiue L, et al. Genome-wide analysis reveals SR protein cooperation and competition in regulated splicing. Mol Cell. 2013;50(2):223-235.

109. Schaal TD, Maniatis T. Multiple distinct splicing enhancers in the protein-coding sequences of a constitutively spliced pre-mRNA. Mol Cell Biol. 1999;19(1):261-273.

110. Liu HX, Chew SL, Cartegni L, et al. Exonic splicing enhancer motif recognized by human SC35 under splicing conditions. Mol Cell Biol. 2000;20(3):1063-1071.

111. Lou H, Neugebauer KM, Gagel RF, et al. Regulation of alternative polyadenylation by U1 snRNPs and SRp20. Mol Cell Biol. 1998;18(9):4977-4985.

112. Cavaloc Y, Bourgeois CF, Kister L, et al. The splicing factors 9G8 and SRp20 transactivate splicing through different and specific enhancers. RNA. 1999;5(3):468-483.

113. Zheng ZM, He PJ, Baker CC. Structural, functional, and protein binding analyses of bovine papillomavirus type 1 exonic splicing enhancers. $J$ Virol. 1997;71(12):9096-9107.

114. Anko ML, Muller-McNicoll M, Brandl H, et al. The RNA-binding landscapes of two SR proteins reveal unique functions and binding to diverse RNA classes. Genome Biol. 2012;13(3):R17.

115. Tacke R, Chen Y, Manley JL. Sequence-specific RNA binding by an SR protein requires RS domain phosphorylation: creation of an SRp40-specific splicing enhancer. Proc Natl Acad Sci U SA. 1997;94(4):1148-1153.

116. Burd CG, Dreyfuss G. RNA binding specificity of hnRNP A1: significance of hnRNP A1 high-affinity binding sites in pre-mRNA splicing. EMBO J. 1994;13(5):1197-1204. 
117. Huelga SC, Vu AQ, Arnold JD, et al. Integrative genome-wide analysis reveals cooperative regulation of alternative splicing by hnRNP proteins Cell Rep. 2012;1(2):167-178.

118. McKay SJ, Cooke H. hnRNP A2/B1 binds specifically to single stranded vertebrate telomeric repeat TTAGGGn. Nucleic Acids Res. 1992;20(24):6461-6464.

119. Hutchison S, LeBel C, Blanchette M, et al. Distinct sets of adjacent heterogeneous nuclear ribonucleoprotein (hnRNP) A1/A2 binding sites control 5' splice site selection in the hnRNP A1 mRNA precursor. $J$ Biol Chem. 2002;277(33):29745-29752.

120. Konig J, Zarnack K, Rot G, et al. iCLIP reveals the function of hnRNP particles in splicing at individual nucleotide resolution. Nat Struct Mol Biol. 2010;17(7):909-915.

121. Shetty S. Regulation of urokinase receptor mRNA stability by hnRNP C in lung epithelial cells. Mol Cell Biochem. 2005;272(1-2):107-118.

122. Matunis MJ, Xing J, Dreyfuss G. The hnRNP F protein: unique primary structure, nucleic acid-binding properties, and subcellular localization. Nucleic Acids Res. 1994;22(6):1059-1067.

123. Xue Y, Zhou Y, Wu T, et al. Genome-wide analysis of PTB-RNA interactions reveals a strategy used by the general splicing repressor to modulate exon inclusion or skipping. Mol Cell. 2009;36(6):996-1006.

124. Masuda A, Andersen HS, Doktor TK, et al. CUGBP1 and MBNL1 preferentially bind to 3' UTRs and facilitate mRNA decay. Sci Rep. 2012;2:209

125. Hui J, Hung LH, Heiner M, et al. Intronic CA-repeat and CA-rich elements: a new class of regulators of mammalian alternative splicing. EMBO J. 2005;24(11):1988-1998.

126. Rossbach O, Hung LH, Khrameeva E, et al. Crosslinkingimmunoprecipitation (iCLIP) analysis reveals global regulatory roles of hnRNP L. RNA Biol. 2014;11(2):146-155.

127. Topp JD, Jackson J, Melton AA, et al. A cell-based screen for splicing regulators identifies hnRNP LL as a distinct signal-induced repressor of CD45 variable exon 4. RNA. 2008;14(10):2038-2049.

128. Smith SA, Ray D, Cook KB, et al. Paralogs hnRNP L and hnRNP LL exhibit overlapping but distinct RNA binding constraints. PLoS One. 2013;8(11):e80701.

129. Vlasova IA, Tahoe NM, Fan D, et al. Conserved GU-rich elements mediate mRNA decay by binding to CUG-binding protein 1 . Mol Cell. 2008;29(2):263-270.

130. Faustino NA, Cooper TA. Identification of putative new splicing targets for ETR-3 using sequences identified by systematic evolution of ligands by exponential enrichment. Mol Cell Biol. 2005;25(3):879-887.

131. Wagnon JL, Briese M, Sun W, et al. CELF4 regulates translation and local abundance of a vast set of mRNAs, including genes associated with regulation of synaptic function. PLoS Genet. 2012;8(11):e1003067.

132. Galarneau A, Richard S. The STAR RNA binding proteins GLD-1, QKI, SAM68 and SLM-2 bind bipartite RNA motifs. BMC Mol Biol. 2009;10:47

133. Galarneau A, Richard S. Target RNA motif and target mRNAs of the Quaking STAR protein. Nat Struct Mol Biol. 2005;12(8):691-698.

134. Hino S, Kondo S, Sekiya H, et al. Molecular mechanisms responsible for aberrant splicing of SERCA1 in myotonic dystrophy type 1. Hum Mol Genet. 2007;16(23):2834-2843.

135. Timchenko LT, Timchenko NA, Caskey CT, et al. Novel proteins with binding specificity for DNA CTG repeats and RNA CUG repeats: Implications for myotonic dystrophy. Hum Mol Genet. 1996;5(1):115-121.
136. Zhou HL, Baraniak AP, Lou H. Role for Fox-1/Fox-2 in mediating the neuronal pathway of calcitonin/calcitonin gene-related peptide alternative RNA processing. Mol Cell Biol. 2007;27(3):830-841.

137. Licatalosi DD, Mele A, Fak JJ, et al. HITS-CLIP yields genomewide insights into brain alternative RNA processing. Nature. 2008;456(7221):464-469.

138. Ule J, Jensen KB, Ruggiu M, et al. CLIP identifies Nova-regulated RNA networks in the brain. Science. 2003;302(5648):1212-1215.

139. Dember LM, Kim ND, Liu KQ, et al. Individual RNA recognition motifs of TIA-1 and TIAR have different RNA binding specificities. $J$ Biol Chem. 1996;271(5):2783-2788.

140. Ashiya M, Grabowski PJ. A neuron-specific splicing switch mediated by an array of pre-mRNA repressor sites: evidence of a regulatory role for the polypyrimidine tract binding protein and a brain-specific PTB counterpart. RNA. 1997;3(9):996-1015.

141. Lin JC, Tarn WY. Exon selection in alpha-tropomyosin mRNA is regulated by the antagonistic action of RBM4 and PTB. Mol Cell Biol. 2005;25(22):10111-10121

142. Lin JC, Tarn WY. RBM4 down-regulates PTB and antagonizes its activity in muscle cell-specific alternative splicing. $J$ Cell Biol. 2011;193(3):509-520

143. Song ZW, Wu PW, Ji P, et al. Solution Structure of the Second RRM Domain of RBM5 and its unusual binding characters for different RNA targets. Biochemistry. 2012;51(33):6667-6678

144. Fushimi K, Ray P, Kar A, et al. Up-regulation of the proapoptotic caspase 2 splicing isoform by a candidate tumor suppressor, RBM5. Proc Nat Acad Sci U S A. 2008;105(41):15708-15713.

145. Bechara EG, Sebestyen E, Bernardis I, et al. RBM5, 6, and 10 differentially regulate $N U M B$ alternative splicing to control cancer cell proliferation. Mol Cell. 2013;52(5):720-733.

146. Maatz H, Jens M, Liss M, et al. RNA-binding protein RBM20 represses splicing to orchestrate cardiac pre-mRNA processing. $J$ Clin Invest. 2014;124(8):3419-3430.

147. Warzecha CC, Sato TK, Nabet B, et al. ESRP1 and ESRP2 Are Epithelial Cell-Type-Specific Regulators of FGFR2 Splicing. Mol Cell. 2009;33(5):591-601.

148. Villablanca A, Calender A, Forsberg L, et al. Germline and de novo mutations in the HRPT2 tumour suppressor gene in familial isolated hyperparathyroidism (FIHP). J Med Genet. 2004;41(3):e32.

149. Bradley KJ, Cavaco BM, Bowl MR, et al. Utilisation of a cryptic noncanonical donor splice site of the gene encoding PARAFIBROMIN is associated with familial isolated primary hyperparathyroidism. $J$ Med Genet. 2005;42(8):e51.

150. Ohno K, Anlar B, Ozdirim E, et al. Myasthenic syndromes in Turkish kinships due to mutations in the acetylcholine receptor. Ann Neurol. 1998;44(2):234-241

151. Kuivenhoven JA, Weibusch H, Pritchard PH, et al. An intronic mutation in a lariat branchpoint sequence is a direct cause of an inherited human disorder (fish-eye disease). J Clin Invest. 1996;98(2):358-364.

152. Crotti L, Lewandowska MA, Schwartz PJ, et al. A $\mathrm{KCNH} 2$ branch point mutation causing aberrant splicing contributes to an explanation of genotype-negative long QT syndrome. Heart Rhythm. $2009 ; 6(2): 212-218$

153. Maslen C, Babcock D, Raghunath M, et al. A rare branch-point mutation is associated with missplicing of fibrillin-2 in a large family with congenita contractural arachnodactyly. Am J Hum Genet. 1997;60(6):1389-1398. 
154. Mattioli C, Pianigiani G, De Rocco D, et al. Unusual splice site mutations disrupt FANCA exon 8 definition. Biochim Biophys Acta. 2014;1842(7):1052-1058.

155. Lefevre SH, Chauveinc L, Lyonnet DS, et al. A T to $\mathrm{C}$ mutation in the polypyrimidine tract of the exon 9 splicing site of the RB1 gene responsible for low penetrance hereditary retinoblastoma. J Med Genet. 2002;39(5):E21.

156. Yu C, Meng X, Zhang S, et al. A 3-nucleotide deletion in the polypyrimidine tract of intron 7 of the DFNA5 gene causes nonsyndromic hearing impairment in a Chinese family. Genomics. 2003;82(5):575-579.

157. Moon SD, Park JH, Kim EM, et al. A Novel IVS2-1G $>$ A mutation causes aberrant splicing of the HRPT2 gene in a family with hyperparathyroidism-jaw tumor syndrome. $J$ Clin Endocrinol Metab. 2005;90(2):878-883.

158. Miyamoto T, Inoue H, Sakamoto $\mathrm{Y}$, et al. Identification of a novel splice site mutation of the CSPG2 gene in a Japanese family with Wagner syndrome. Invest Ophthalmol Vis Sci. 2005;46(8):2726-2735.

159. Ohno K, Tsujino A, Shen XM, et al. Spectrum of splicing errors caused by CHRNE mutations affecting introns and intron/exon boundaries. $J$ Med Genet. 2005;42(8):e53.

160. Kimbell LM, Ohno K, Engel AG, et al. C-terminal and heparinbinding domains of collagenic tail subunit are both essential for anchoring acetylcholinesterase at the synapse. J Biol Chem. 2004;279(12):10997-11005

161. Lee VMY, Goedert M, Trojanowski JQ. Neurodegenerative tauopathies Annu Rev Neurosci. 2001;24:1121-1159.

162. Jacobsen M, Schweer D, Ziegler A, et al. A point mutation in PTPRC is associated with the development of multiple sclerosis. Nat Genet. 2000;26(4):495-499.

163. Cogan JD, Prince MA, Lekhakula S, et al. A novel mechanism of aberrant pre-mRNA splicing in humans. Hum Mol Genet. 1997;6(6):909-912.

164. Santoro A, Cannella S, Trizzino A, et al. Mutations affecting mRNA splicing are the most common molecular defect in patients with familial hemophagocytic lymphohistiocytosis type 3. Haematologica $J$. 2008;93(7):1086-1090.

165. Hobson GM, Huang Z, Sperle K, et al. A PLP splicing abnormality is associated with an unusual presentation of PMD. Ann Neurol. 2002;52(4):477-488.

166. Pagani F, Buratti E, Stuani C, et al. A new type of mutation causes a splicing defect in ATM. Nat Genet. 2002;30(4):426-429.

167. Metherell LA, Akker SA, Munroe PB, et al. Pseudoexon activation as a novel mechanism for disease resulting in atypical growth-hormone insensitivity. Am J Hum Genet. 2001;69(3):641-646.

168. Lee EB, Lee VM, Trojanowski JQ. Gains or losses: molecular mechanisms of TDP43-mediated neurodegeneration. Nat Rev Neurosci. 2011;13(1):38-50

169. Kwiatkowski TJ, Vanderburg CR, Bosco DA, et al. Mutations in the FUS/TLS gene on chromosome 16 cause familial amyotrophic lateral sclerosis. Science. 2009;323(5918):1208-1208.

170. Vance C, Rogelj B, Hortobagyi T, et al. Mutations in FUS, an RNA Processing Protein, Cause Familial Amyotrophic Lateral Sclerosis Type 6. Science. 2009;323(5918):1208-1211.

171. Fogel BL, Wexler E, Wahnich A, et al. RBFOX1 regulates both splicing and transcriptional networks in human neuronal development. Hum Mol Genet. 2012;21(19):4171-4186.

172. Voineagu I, Wang XC, Johnston $\mathrm{P}$, et al. Transcriptomic analysis of autistic brain reveals convergent molecular pathology. Nature. 2011;474(7351):380-384
173. Kim HJ, Kim NC, Wang YD, et al. Mutations in prion-like domains in hnRNPA2B1 and hnRNPA1 cause multisystem proteinopathy and ALS. Nature. 2013;495(7442):467-473.

174. Jensen KB, Dredge BK, Stefani G, et al. Nova-1 regulates neuronspecific alternative splicing and is essential for neuronal viability. Neuron. 2000;25(2):359-371.

175. Ule J, Ule A, Spencer J, et al. Nova regulates brain-specific splicing to shape the synapse. Nat Genet. 2005;37(8):844-852.

176. Stamm S, Zhu J, Nakai K, et al. An alternative-exon database and it statistical analysis. DNA Cell Biol. 2000;19(12):739-756.

177. Martelli PL, D’Antonio M, Bonizzoni P, et al. ASPicDB: a database of annotated transcript and protein variants generated by alternative splicing. Nucleic Acids Res. 2011;39:D80-85.

178. Cooper DN, Ball EV, Krawczak M. The human gene mutation database. Nucleic Acids Res. 1998;26(1):285-287.

179. Yang JO, Kim WY, Bhak J. ssSNPTarget: Genome-wide Splice-site Single Nucleotide Polymorphism Database. Hum Mutat. 2009;30(12):E1010 E1020.

180. Sherry ST, Ward MH, Kholodov M, et al. dbSNP: the NCBI database of genetic variation. Nucleic Acids Res. 2001;29(1):308-311.

181. Abecasis GR, Auton A, Brooks LD, et al. An integrated map of genetic variation from 1,092 human genomes. Nature. 2012;491(7422):56-65

182. Narahara M, Higasa K, Nakamura S, et al. Large-Scale East-Asian eQTL Mapping Reveals Novel Candidate Genes for LD Mapping and the Genomic Landscape of Transcriptional Effects of Sequence Variants. PLoS One. 2014;9(6):e100924.

183. Desmet FO, Hamroun D, Lalande M, et al. Human Splicing Finder: an online bioinformatics tool to predict splicing signals. Nucleic Acids Res. 2009;37(9):e67.

184. Yeo G, Burge CB. Maximum entropy modeling of short sequence motifs with applications to RNA splicing signals. J Comput Biol. 2004;11(2-3):377-394.

185. Shapiro MB, Senapathy P. Rna Splice Junctions of Different Classes of Eukaryotes - Sequence Statistics and Functional Implications in GeneExpression. Nucleic Acids Res. 1987;15(17):7155-7174.

186. Shapiro MB, Senapathy P. Automated Preparation of DNA-Sequences for Publication. Nucleic Acids Res. 1986;14(1):65-73.

187. Buratti E, Chivers M, Hwang G, et al. DBASS3 and DBASS5: databases of aberrant 3'- and 5'-splice sites. Nucleic Acids Res. 2011;39:D86-D91.

188. Piva F, Giulietti M, Nocchi L, et al. SpliceAid: a database of experimental RNA target motifs bound by splicing proteins in humans. Bioinformatics. 2009;25(9):1211-1213.

189. Piva F, Giulietti M, Burini AB, et al. SpliceAid 2: A Database of Human Splicing Factors Expression Data and RNA Target Motifs. Hum Mutat. 2012;33(1):81-85.

190. Cartegni L, Wang JH, Zhu ZW, et al. ESEfinder: a web resource to identify exonic splicing enhancers. Nucleic Acids Res. 2003;31(13):3568-3571.

191. Smith PJ, Zhang CL, Wang JH, et al. An increased specificity score matrix for the prediction of SF2/ASF-specific exonic splicing enhancers. Hum Mol Genet. 2006;15(16):2490-2508.

192. Fairbrother WG, Yeh RF, Sharp PA, et al. Predictive identification of exonic splicing enhancers in human genes. Science. 2002;297(5583):1007-1013.

193. Fairbrother WG, Yeo GW, Yeh R, et al. RESCUE-ESE identifies candidate exonic splicing enhancers in vertebrate exons. Nucleic Acids Res. 2004;32:W187-W190. 
194. Wang Z, Rolish ME, Yeo G, et al. Systematic identification and analysis of exonic splicing silencers. Cell. 2004;119(6):831-845.

195. Paz I, Akerman M, Dror I, et al. SFmap: a web server for motif analysis and prediction of splicing factor binding sites. Nucleic Acids Res. 2010;38:W281-W285.

196. Zuker M. Mfold web server for nucleic acid folding and hybridization prediction. Nucleic Acids Res. 2003;31(13):3406-3415.
197. Ding Y, Chan CY, Lawrence CE. Sfold web server for statistical folding and rational design of nucleic acids. Nucleic Acids Res. 2004;32:W135W141.

198. Knudsen B, Hein J. Pfold: RNA secondary structure prediction using stochastic context-free grammars. Nucleic Acids Res. 2003;31(13):3423-3428. 